\title{
The Cross-section of Firms over the Business Cycle: New Facts and a DSGE Exploration
}

\author{
Ruediger Bachmann Christian Bayer*
}

April 8, 2009

\begin{abstract}
Using a unique German firm-level data set, this paper is the first to jointly study the cyclical properties of the cross-sections of firm-level real value added and Solow residual innovations, as well as capital and employment adjustment. We find two new business cycle facts: 1) The cross-sectional standard deviation of firm-level innovations in the Solow residual, value added and employment is robustly and significantly countercyclical. 2) The cross-sectional standard deviation of firm-level investment is procyclical. We show that a heterogeneous-firm RBC model with quantitatively realistic countercyclical innovations in the firm-level Solow residual and non-convex adjustment costs calibrated to the nonGaussian features of the steady state investment rate distribution, produces investment dispersion that positively comoves with the cycle, with a correlation coefficient of 0.65 , compared to 0.61 in the data. We argue more generally that the cross-sectional business cycle dynamics impose tight empirical restrictions on structural parameters and stochastic properties of driving forces in heterogeneous-firm models, and are therefore paramount in the calibration of these models.
\end{abstract}

JEL Codes: E20, E22, E30, E32.

Keywords: Ss model, RBC model, cross-sectional firm dynamics, lumpy investment, countercyclical risk, aggregate shocks, idiosyncratic shocks, heterogeneous firms.

\footnotetext{
* Respectively: University of Michigan; IGIER, Universitá Bocconi. We are grateful to seminar/meeting participants at the ASSA (San Francisco), Duke, Georgetown, Innsbruck, Michigan-Ann Arbor, Minneapolis FED, Wisconsin-Madison and Zuerich for their comments. We thank the staff of the Research Department of Deutsche Bundesbank for their assistance. Special thanks go to Timm Koerting for excellent research assistance.
} 


\section{Introduction}

The cross-section of firms - more specifically the dispersions of change rates of firm-level output, capital, employment and Solow residuals - display stark cyclical patterns. To the best of our knowledge, this is the first paper to systematically document the cyclical properties of these moments of the cross-section of firms. Using the balance sheet data set of Deutsche Bundesbank (USTAN) - a unique private sector, annual, firm-level data set that allows us to investigate 26 years of data (1973-1998), in which the cross-sections of the panel have over 30,000 firms per year on average -, we show that the cross-sectional standard deviations of the firm-level innovations in the Solow residual, value added and employment are robustly and significantly countercyclical, as measured by the contemporaneous correlation with the cyclical component of aggregate output. In contrast, the cross-sectional standard deviation of firm-level investment rates is robustly and significantly procyclical. These results are robust to different filtering methods for aggregate output, to using the cross-sectional interquartile range as a measure of dispersion, to using cyclical indicators other than aggregate output and to various changes in the sample selection criteria. Figure 1 illustrates these two new business cycle facts (see Appendix A.5 for a time series graph of the investment rate dispersion):

Figure 1: Cross-sectional Dispersion of Firm-Level Investment Rates and Solow Residual Innovations
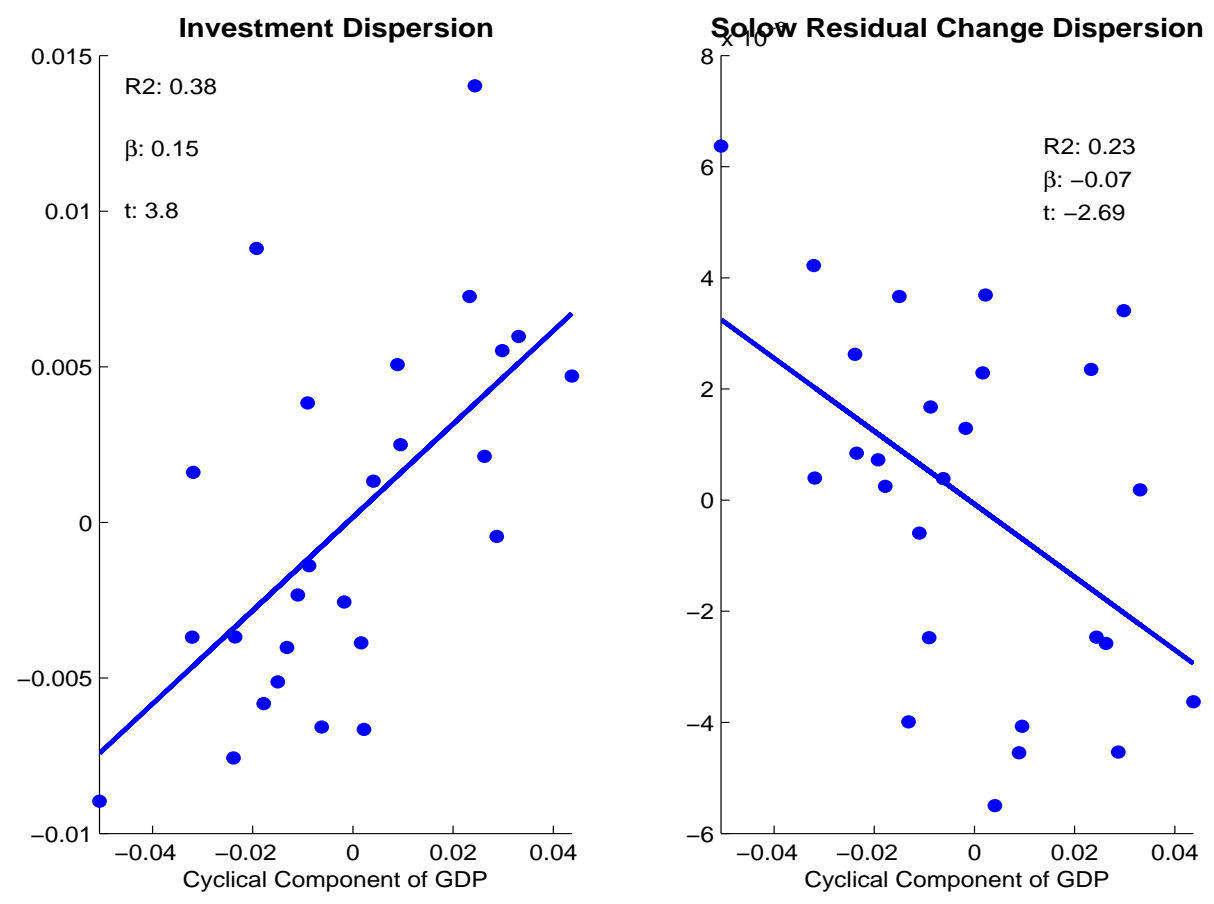

It is clear that this finding is incompatible with a simple frictionless model of the firm with ex ante homogeneous firms, as the latter would imply that the stochastic properties of the driving 
force - dispersion in the innovations to firm-level Solow residuals - are at least qualitatively inherited by the outcome variables. We propose a heterogenous-firm RBC model with persistent idiosyncratic productivity shocks and lumpy capital adjustment to explain both qualitatively and quantitatively the procyclicality of investment dispersion, even in the presence of countercyclical second-moment shocks in the driving force. The basic intuition, why lumpy capital adjustment is at least qualitatively a suitable candidate to explain this fact, can be glanced from the simple Ss-model in Caplin and Spulber (1987):

\section{Proposition:}

In a one-sided Ss-model a la Caplin and Spulber with a uniform gap-distribution, fixed optimal adjustment policy $S-s$ and shock $\Delta z$, the standard deviation of adjustments is increasing in $\Delta z$ if and only if the fraction of adjusters is smaller than 0.5 .

Proof:

As is well known, average adjustment in this environment is $\Delta z$. From this, it follows immediately that the standard deviation of adjustment is: $(0-\Delta z)^{2}\left(1-\frac{\Delta z}{S-s}\right)+((S-s)-\Delta z)^{2}\left(\frac{\Delta z}{S-s}\right)=$ $\Delta z(S-s-\Delta z)$, which is increasing in $\Delta z$ if and only if $\frac{\Delta z}{S-s}<0.5$, where $\frac{\Delta z}{S-s}$ is the fraction of adjusters.

This example shows that with sufficient inertia the comovement of the extensive margin with the cycle leads to a procyclical dispersion of adjustment, as in this simple model all the dynamics are driven by the extensive margin, since the intensive margin of adjustment, $S-s$, is fixed by assumption. We will show that in a more realistic model this extensive margin effect is still operative and can explain the observed procyclicality of investment dispersion almost exactly. We also provide further suggestive evidence that it is most likely lumpy capital adjustment that is generating this result: 1) we show that in sectors like manufacturing and construction, where we would expect non-convex factor adjustment to be most prevalent, procyclicality of investment dispersion is particularly pronounced; 2) we also show that for smaller firms, i.e. firms that are likely incapable of outgrowing adjustment costs, investment dispersion is significantly more procyclical than for the largest firms. In contrast, conditional on firm size, finance variables do not seem to have a large impact on the cyclicality of investment dispersion. We conclude from this that the explanation most likely does not lie in a financial friction. We also find no evidence of a composition effect in the sense that some large sectors or large firms have actually procyclical second-moment shocks that make the overall investment dispersion likewise procyclical.

Why is this important? First, in our view explaining the business cycle dynamics of the higher cross-sectional moments of the underlying macroeconomic aggregates is just as important for our understanding of the business cycle as explaining these aggregates themselves. A 
fully fledged business cycle theory has to speak to these cross-sectional dynamics as well. To the best of our knowledge, our paper is the first to systematically document the relevant facts and explain the most striking of them: procyclical investment dispersion in the presence of countercyclical second-moment shocks. Secondly, heterogenous-firm models have seen increased use both in the macroeconomic as well as international finance literature. We show in this paper that cross-sectional dynamics impose tight restrictions on structural parameters as well as on the nature and stochastic properties of the driving forces in these models. ${ }^{1}$ For instance, we show that procyclical investment dispersion in the presence of countercyclical second-moment shocks is only compatible with a strong capital-curvature of the revenue function of the firm, for there to be a strong enough procyclical extensive margin effect (see Gourio and Kashyap (2007) for a related observation). We also document that the strengths of the countercyclical second-moment shocks must not be too strong to be compatible with procyclical investment dispersion. In particular, countercyclical second-moment shocks as large as suggested by Bloom (2009) and Bloom et al. (2009) and large enough to generate interesting business cycle dynamics are incompatible with this cross-sectional business cycle fact. That means crosssectional dynamics have also strong implications for the nature of aggregate dynamics.

\section{Related Literature}

The empirical part of this paper, section 2, is most closely related to a series of papers by Higson and Holly et al. (2002, 2004), Doepke and Holly et al. (2005, 2008), Doepke and Weber (2006), as well as Holly and Santoro (2008). Higson and Holly et al. (2002), using Compustat data, study empirically the cyclicality of the standard deviation, skewness and kurtosis of the sales growth rate distribution and find them to be countercyclical, countercyclical and procyclical, respectively. Higson and Holly et al. (2004) repeat this analysis for UK data on quoted firms, and Doepke and Holly et al. (2005) for Germany, using the USTAN database, with similar findings. Doepke and Weber (2006) study, again using USTAN data, the cyclicality of transitions between sales growth regimes in firm-level data. In contrast to these papers, we focus on the cyclicality of cross-sectional second moments only, but include value added, Solow residuals, investment rates and employment change rates into the analysis. ${ }^{2}$ The quantitative-theoretical part of this paper - sections 3, 4 and 5-draws heavily on the recent literature on heterogenousfirm RBC models, developed in Khan and Thomas (2008), Bachmann et al. (2008), Bloom (2009), Bloom et al. (2009) as well as Bachmann and Bayer (2009). Finally, our work is related to the work by Eisfeldt and Rampini (2005), who show that capital reallocation is procyclical and explain this in a two-sector model with costly capital reallocation.

\footnotetext{
${ }^{1}$ Khan and Thomas (2005), in an earlier version of their 2008-paper, make a similar observation on the importance of general equilibrium in understanding cross-sectional firm dynamics. We confirm their conjecture here.

${ }^{2}$ Holly and Santoro (2008) as well as Doepke and Holly et al. (2008) start from the aforementioned empirical work and explore them in a monopolistically competitive model with financial frictions - the former - and in a monopolistically competitive model with simple Calvo-type price-stickiness - the latter.
} 


\section{The Facts}

In Section 2.1 we briefly describe the USTAN data set and the main sample selection criteria we use. Details are relegated to Appendix A.1. In Section 2.2 we present the baseline facts: the contemporaneous correlations of cyclical aggregate output and the cross-sectional standard deviations of firm-level Solow residual and real value added innovations as well as employment change rates are negative, while the contemporaneous correlation of cyclical aggregate output and the cross-sectional standard deviation of firm-level investment rates is positive. In Section 2.3 we perform extensive robustness checks and also show, how these facts depend on observable firm characteristics.

\subsection{A Brief Data Description}

\subsubsection{USTAN Data}

USTAN is a large annual firm-level balance sheet data base (Unternehmensbilanzstatistik) collected by Deutsche Bundesbank. It is unique in its size and coverage. It provides annual firm level data from 1971 to 1998 from the balance sheets and the profit and loss accounts of over 60,000 firms per year (see Stoess (2001), von Kalckreuth (2003) and Doepke et al. (2005) for further details). In the days when the discounting of commercial bills were one of the principal instruments of German monetary policy, Bundesbank law required the Bundesbank to assess the creditworthiness of all parties backing a commercial bill put up for discounting. The Bundesbank implemented this regulation by requiring balance sheet data of all parties involved. These balance sheet data were then archived and collected into a database.

Although the sampling design - one's commercial bill being put up for discounting - does not lead to a perfectly representative selection of firms in a statistical sense, the coverage of the sample is very broad. USTAN covers incorporated firms as well as privately-owned companies, which distinguishes it positively from Compustat data. ${ }^{3}$ Its sectoral coverage - while still somewhat biased to manufacturing firms - includes the construction, the service as well as the primary sectors. This makes it different from, for instance, the Annual Survey of Manufacturing (ASM) in the U.S. ${ }^{4}$ The following table 1 displays the sectoral coverage of our final baseline sample.

Moreover, while there remains a bias to somewhat larger and financially healthier firms, the size coverage is still fairly broad: $31 \%$ of all firms in our final baseline sample have less than

\footnotetext{
${ }^{3}$ Davis et al. (2006) show that studying only publicly traded firms can lead to wrong conclusions, in particular when higher cross-sectional moments are concerned.

${ }^{4} \mathrm{An}$ additional advantage of these data is easy access: while access is on-site, it is practically free for researchers, so that results derived from this data base can be easily tested and checked.
} 
Table 1: Sectoral Coverage

\begin{tabular}{lcc}
\hline \hline 1-digit Sector & Firm-year observations & Percentage \\
\hline Agriculture & 12,291 & 1.44 \\
Mining \& Energy & 4,165 & 0.49 \\
Manufacturing & 405,787 & 47.50 \\
Construction & 54,569 & 6.39 \\
Trade (Retail \& Wholesale) & 355,208 & 41.59 \\
Transportation \& Communication & 22,085 & 2.59 \\
\hline
\end{tabular}

20 employees and 57\% have less than 50 employees (see Table 17 in Appendix A.1 for details). Finally, the Bundesbank itself frequently uses the USTAN data for its macroeconomic analyses and for cross-checking national accounting data. We take this as an indication that the bank considers the data as sufficiently representative and of sufficiently high quality. This makes the USTAN data a uniquely suitable data source for the study of cross-sectional business cycle dynamics.

\subsubsection{Selection of the Baseline Sample}

From the original USTAN data, we select only firms that report complete information on payroll, gross value added and capital stocks. Moreover, we drop observations from East German firms to avoid a break of the series in 1990. In addition, we remove observations that stem from irregular accounting statements, e.g. when filing for bankruptcy or when closing operations. We deflate all but the capital and investment data by the implicit deflator for gross value added from the German national accounts.

Capital is deflated with one-digit sector- and capital-good specific investment good price deflators within a perpetual inventory method. Even though USTAN data can be considered as particularly high quality data, we cannot directly use capital stocks as reported. Tax motivated depreciation and price developments of capital goods lead to a general understatement of the stock of capital a firm holds. Thus, capital stocks have to be recalculated using a perpetual inventory method (see Appendix A.2, for details). Similarly, we recover the amount of labor inputs from wage bills, as information on the number of employees (as opposed to payroll data) is only updated infrequently for some companies (see Appendix A.3, for details). Finally, the firm-level Solow residual is calculated from data on gross value added and factor inputs.

We remove outliers according to the following procedure: we calculate log changes in real gross value added, the Solow residual, real capital and employment, as well as the firm-level investment rate and drop all observations where a change falls outside a three standard deviations 
interval around the year-specific mean. ${ }^{5}$ We also drop those firms for which we do not have at least five observations in first differences. This leaves us with a sample of 854,105 firm-year observations, which corresponds to observations on 72,853 firms, i.e. the average observation length of a firm in the sample is 11.7 years. The average number of firms in the cross-section of any given year is 32,850 . We perform numerous robustness checks with respect to each of the selection criteria and measurement choices: we use sectoral deflators for value added, an aggregate investment good price deflator, change the cut-off rule to 2.5 and 5 standard deviations and leave all firms in the sample with two and twenty observations in first differences, respectively. None of these choices change our baseline results (see Appendix B for details).

\subsubsection{Calculating the Solow Residual and Factor Adjustments}

We compute the firm-level Solow residual based on the following Cobb-Douglas production function in accordance with our model:

$$
y_{i, t}=z_{t} \epsilon_{i, t} k_{i, t}^{\theta} n_{i, t}^{v}
$$

where $\epsilon_{i, t}$ is firm-specific productivity, and $z_{t}$ is aggregate productivity. We assume that labor input $n_{i, t}$ is immediately productive, whereas capital $k_{i, t}$ is pre-determined and inherited from last period. In our main specification, we estimate the output elasticities of the production factors, $v$ and $\theta$, as median shares of factor expenditures over gross value added within each industry. ${ }^{6}$

For factor adjustment, we use the symmetric adjustment rate definition proposed in Davis et al. (1996). We thus define firm-level investment rates as $\frac{i_{i, t}}{0.5 *\left(k_{i, t}+k_{i, t+1}\right)}{ }^{7}$ and firm-level employment adjustment rates as $\frac{\Delta n_{i, t}}{0.5 *\left(n_{i, t-1}+n_{i, t}\right)} .{ }^{8}$ We use log-differences in the Solow residual to capture Solow residual innovations, as the persistence of firm-level Solow residuals exhibits behavior close to a unit root. We remove firm fixed and sectoral-year ${ }^{9}$ effects from these firstdifference variables to focus on idiosyncratic fluctuations that do not capture differences in sectoral responses to aggregate shocks or permanent ex-ante heterogeneity between firms.

\footnotetext{
${ }^{5}$ This outlier removal is done after removing firm and sectoral fixed effects. Centering the outlier removal around the year mean is important to avoid artificial and countercyclical skewness of the respective distributions.

${ }^{6}$ To check the robustness of our results, we try alternative specifications with predefined elasticities common across sectors. We also change the timing assumption to include a predetermined employment stock, as well as immediate adjustment in both factors. All results are very robust to the various ways of generating the firm-specific Solow residual (for a detailed discussion, see Bachmann and Bayer, 2009).

${ }^{7}$ Appendix A.1 compares the USTAN investment rate histogram with the U.S. one from the Longitudinal Research Database, LRD. The similarities are remarkable, which suggests the generalizability of our results also to the U.S.

${ }^{8}$ The baseline within-transformed cross-sectional dispersion data for factor adjustments can be found in Table 22 in Appendix A.6.

${ }^{9}$ The sectoral fixed effects are essentially computed at the 2-digit level, see Table 16 in Appendix A.1 for details.
} 


\subsubsection{Macro data}

When combining this micro data with aggregate data, we have to take a stance on what sectoral aggregate we view as the empirical counterpart to our model. We chose to include firms from the following six sectors in our analysis: agriculture, mining and energy, manufacturing, construction, trade (both retail and wholesale) as well as the transportation and communication sector. This aggregate can be roughly characterized as the non-financial private business sector in Germany. Whenever we use the term aggregate in the following, we mean this sector.

German national accounting data per one-digit sector (see Appendix A.1 for a detailed description of the data sources used) allow us to compute real value added, investment, capital and employment data for this sectoral aggregate, and therefore also an aggregate Solow residual. Our USTAN sample captures on average $70 \%$ of sectoral value added, $44 \%$ of sectoral investment, $71 \%$ of its capital stock and $49 \%$ of sectoral employment.

In addition to representing a large part of the non-financial private business sector in Germany, USTAN also represents its cyclical behavior very well, as the following Table 2 shows: ${ }^{10}$

Table 2: Cyclicality of Cross-Sectional Averages

\begin{tabular}{lc}
\hline \hline Cross-sectional Moment & $\rho(\cdot, H P(100)-Y)$ \\
\hline $\operatorname{mean}\left(\frac{i_{i, t}}{0.5 *\left(k_{i, t}+k_{i, t+1}\right)}\right)$ & 0.792 \\
$\operatorname{mean}\left(\Delta \log \epsilon_{i, t}\right)$ & 0.592 \\
$\operatorname{mean}\left(\Delta \log y_{i, t}\right)$ & 0.663 \\
$\operatorname{mean}\left(\frac{\Delta n_{i, t}}{0.5 *\left(n_{i, t-1}+n_{i, t}\right)}\right)$ & 0.602 \\
\hline
\end{tabular}

Notes:

$\rho$ : correlation coefficient.

$H P(\lambda)-Y$ : Cyclical component of GDP after HP-filtering using smoothing parameter $\lambda$.

\subsection{Main Facts}

The following Table 3 presents the main new stylized facts about the cross-sectional dynamics of firms. Firm-level investment rates display procyclical dispersion, whereas the cross-sectional standard deviations of the (log)-changes in Solow residuals, output and employment are countercyclical.

The first column of Table 3 shows the contemporaneous correlation of the cyclical component of aggregate output ${ }^{11}$ with the cross-sectional standard deviations of the firm-level investment rates, the percentage changes in the firm-level Solow residual and real value added as well as employment changes. The first is clearly procyclical, the latter three countercyclical.

\footnotetext{
${ }^{10}$ We further document the good representation properties of USTAN in Appendix A.1.

${ }^{11}$ For the baseline scenario we use log-output with an HP-parameter 100.
} 
Table 3: CyclicAlity of Cross-Sectional Dispersion

\begin{tabular}{lcccc}
\hline \hline Cross-sectional Moment & $\rho(\cdot, H P(100)-Y)$ & $5 \%$ & $95 \%$ & Frac. w. opposite sign \\
\hline$\sigma\left(\frac{i_{i, t}}{0.5 *\left(k_{i, t}+k_{i, t+1}\right)}\right)$ & 0.613 & 0.338 & 0.784 & 0.001 \\
$\sigma\left(\Delta \log \epsilon_{i, t}\right)$ & -0.481 & -0.678 & -0.306 & 0.000 \\
$\sigma\left(\Delta \log y_{i, t}\right)$ & -0.450 & -0.675 & -0.196 & 0.005 \\
$\sigma\left(\frac{\Delta n_{i, t}}{0.5 *\left(n_{i, t-1}+n_{i, t}\right)}\right)$ & -0.498 & -0.717 & -0.259 & 0.001 \\
\hline
\end{tabular}

Notes:

$\sigma$ : cross-sectional standard deviation, linearly detrended.

The columns 5\% and 95\% refer to the top and bottom 5-percentiles in a parametric bootstrap of the correlation coefficient. The last column displays the fraction of simulations with the opposite sign of the point estimate. See further notes to Table 2 .

The next two columns show the 5\% and 95\% confidence bands from 10,000 parametric bootstrap simulations. ${ }^{12}$ The last column displays the fraction of negative correlations for the standard deviation of the firm-level investment rates, and the fraction of positive correlations for the remaining three standard deviations in these bootstrap simulations. These three columns together show that the sign of all correlations is significant. In the following, we show that finding a procyclical investment rate dispersion is robust to the specific choices we have made in generating the numbers in Table 3.

\subsection{Robustness}

Table 4: Procyclicality of Cross-Sectional Investment Dispersion - Robustness to CYCLICAL INDICATOR

\begin{tabular}{lc}
\hline \hline Cyclical Indicator & $\rho\left(\sigma\left(\frac{i_{i, t}}{0.5 *\left(k_{i, t}+k_{i, t+1}\right)}\right), \cdot\right)$ \\
\hline HP(6.25)-Y & 0.529 \\
Log-diff-Y & 0.419 \\
mean $\left(\frac{i_{i, t}}{0.5 *\left(k_{i, t}+k_{i, t+1}\right)}\right)$ & 0.834 \\
HP(100)-N & 0.533 \\
HP(100)-Solow Residual & 0.511 \\
\hline
\end{tabular}

Notes: See notes to Tables 2 and 3. $N$ refers to aggregate employment.

Table 4 shows that procyclical investment dispersion is robust to the choice of the cyclical indicator. ${ }^{13}$ The result stands irrespective of whether we choose as cyclical indicators output

\footnotetext{
${ }^{12}$ We use a pairwise unrestricted VAR with one lag as the parametric model. The results from a nonparametric overlapping block bootstrap with a block size of four are similar to the parametric bootstrap.

${ }^{13}$ This is also true for the three other variables, and for $\sigma\left(\Delta \log \epsilon_{i, t}\right)$ and $\sigma\left(\Delta \log y_{i, t}\right)$, we have documented this and other robustness tests elsewhere: Bachmann and Bayer (2009). 
filtered using a smaller smoothing parameter for the HP filter, following Ravn and Uhlig (2002), apply a log-difference filter to output, or use the linearly detrended average cross-sectional investment rate, or the HP(100)-filtered aggregate employment, or aggregate Solow residuals.

Vice versa, our finding is also robust to the numerous choices we have made for the other part of the correlation, see Table 5. One can use the interquartile range (IQR) as the dispersion measure, and one can study the firm level net percentage change in capital as opposed to the investment rate. Moreover, it is not the removal of firm-level and sectoral fixed effects inducing this procyclicality, as row three of this table shows. Finally, the last two rows demonstrate that the result is neither driven by the German reunification, nor by the strong recession in 1975 .

Table 5: Procyclicality of Cross-Sectional Investment Dispersion - More Robustness

\begin{tabular}{lc}
\hline \hline Cross-sectional Moment & $\rho(\cdot, H P(100)-Y)$ \\
\hline $\operatorname{IQR}\left(\frac{i_{i, t}}{0.5 *\left(k_{i, t}+k_{i, t+1}\right)}\right)$ & 0.647 \\
$\sigma\left(\Delta \log k_{i, t}\right)$ & 0.442 \\
$\sigma\left(\frac{i_{i, t}}{0.5 *\left(k_{i, t}+k_{i, t+1}\right)}\right)_{\text {raw }}$ & 0.653 \\
$\sigma\left(\frac{i_{i, t}}{0.5 *\left(k_{i, t}+k_{i, t+1}\right)}\right)_{1973-1990}$ & 0.538 \\
$\sigma\left(\frac{i_{i, t}}{0.5 *\left(k_{i, t}+k_{i, t+1}\right)}\right)_{1977-1998}$ & 0.539 \\
\hline
\end{tabular}

Notes: See notes to Tables 2 and 3. IQR stands for interquartile range, which is linearly detrended.

Tables 6 and 7 show how the cyclicality of cross-sectional investment dispersion manifests itself across sectors and firm sizes. We use again the cross-sectional standard deviation of the firm-level investment rate and the HP(100)-filtered log-output of the sectoral aggregate as inputs into the correlation measure.

Table 6: Cyclicality of Cross-Sectional Investment Dispersion - SeCtors

\begin{tabular}{lcc}
\hline \hline 1-digit Sector & $\rho\left(\sigma\left(\frac{i_{i, t}}{0.5 *\left(k_{i, t}+k_{i, t+1}\right)}\right), H P(100)-Y\right)$ & $\rho\left(\sigma\left(\Delta \log \epsilon_{i, t}\right), H P(100)-Y\right)$ \\
\hline Agriculture & 0.074 & -0.045 \\
Mining \& Energy & 0.063 & -0.166 \\
Manufacturing & 0.509 & -0.607 \\
Construction & 0.480 & -0.483 \\
Trade (Retail \& Wholesale) & 0.449 & -0.192 \\
Transportation \& Communication & 0.219 & -0.036 \\
\hline
\end{tabular}

Notes: See notes to Tables 2 and 3.

Table 6 shows that procyclicality of investment dispersion is strongly prevalent in the goodsproducing sectors, manufacturing and construction, as well as trade, which together make up 
$95 \%$ of all observations in the sample. The transportation and communication sector exhibits a much smaller effect, whereas in the primary sectors investment dispersion is nearly acyclical. To put these findings in perspective, we also display the cyclicality of the cross-sectional innovations-to-Solow-residual dispersion, which - despite the procyclicality of investment dispersion - is strongly countercyclical in the goods-producing sectors. Conversely, in the primary sectors both dispersions of driving forces and outcome variables are acyclical.

Table 7: Cyclicality of Cross-Sectional Investment Dispersion - Firm Size

\begin{tabular}{lccc}
\hline \hline Size Class / Criterion & Capital & Employment & Value Added \\
\hline Smallest 33\% & 0.516 & 0.582 & 0.574 \\
Smallest 75\% & 0.653 & 0.644 & 0.644 \\
Smallest 95\% & 0.634 & 0.638 & 0.645 \\
Largest 5\% & 0.182 & 0.109 & 0.012 \\
\hline
\end{tabular}

As Table 7 shows, procyclicality of investment dispersion is driven mainly by the smaller firms, independently of whether size is measured by capital holdings, employment or value added. Large firms, in contrast, display only weakly procyclical to acyclical investment dispersion. This distinction is significant in the sense that at least if size is measured in terms of employment or value added, neither the point estimate for the smallest size class lies in the $[5 \%, 95 \%]$-bands of the largest size class nor vice versa. For capital, the point estimate for the smallest size class falls into the $[5 \%, 95 \%]$-bands of the largest size class, but not vice versa. ${ }^{14}$

Finally, the last Table 8 shows that conditional on firm size - as measured by capital - the financial situation of a firm - as measured by the equity-asset-ratio - hardly matters for the cyclicality of investment dispersion:

Table 8: Cyclicality of Cross-Sectional Investment Dispersion - FinAnCial Situation

\begin{tabular}{lcc}
\hline \hline Equity-Asset-Ratio Tercile & Smallest 33\% - Capital & Largest 5\% - Capital \\
\hline First & 0.487 & 0.072 \\
Second & 0.292 & 0.068 \\
Third & 0.377 & -0.151 \\
\hline
\end{tabular}

Tables 6 to 8 together with the finding that the Solow residual processes for small and large firms hardly differ both on average over time and in terms of cyclicality of their innovations, ${ }^{15}$ at least suggests that the friction necessary to explain the differential cyclicality of the dispersions

\footnotetext{
${ }^{14}$ See Appendix A.1 for detailed information on the size distribution of firms in our sample.

${ }^{15}$ See Bachmann and Bayer (2009) for an in-depth discussion of this fact.
} 
of firm-level innovations-to-Solow-residual and investment rates, respectively, can neither be found in financial constraints nor in different shock processes. It also does not appear to be driven by certain sectors and large firms. Instead, we will show that the presence of lumpy capital adjustment is a plausible cause for this aspect of the cross-sectional firm dynamics. Indeed, the fact that procyclical investment dispersion is mostly prevalent in the goods-producing sectors as well as in smaller firms, i.e. firms where we would a priori expect non-convexities in the adjustment technology to be more relevant, is at least consistent with our explanation.

\section{The Model}

In this section we describe our model economy. We start with the firm's problem, followed by a brief description of the households and the definition of equilibrium. We conclude with a sketch of the equilibrium computation. We follow closely Khan and Thomas (2008) and Bachmann et al. (2008). Since there the model set up is discussed in detail, we will be rather brief here.

The main departure from either papers is the introduction of a second exogenous aggregate state, the standard deviation of the current idiosyncratic shock distribution: $\sigma(\epsilon)$. The motivation for this is both realism, as we find these second-moment shocks in the data, but also conservatism: we will show in Section 5.1 that without countercyclical second-moment shocks even with very small fixed costs to adjustment the investment rate dispersion is very procyclical, even more procyclical than in the data. This comes as no surprise, as without countercyclical second-moment shocks there is no countervailing force that would undo the extensive margin effect that in turn causes the investment rate dispersion to be procyclical. Thus, since this is a quantitative exercise using the correct amount of second-moment volatility and countercyclicality in the driving force is important. Following Khan and Thomas (2008), we approximate this now bivariate aggregate state process with a discrete Markov chain.

\subsection{Firms}

The economy consists of a unit mass of small firms. We do not model entry and exit decisions. There is one commodity in the economy that can be consumed or invested. Each firm produces this commodity, employing its pre-determined capital stock $(k)$ and labor $(n)$, according to the following Cobb-Douglas decreasing-returns-to-scale production function $(\theta>0, v>0, \theta+v<$ 1):

$$
y=z \epsilon k^{\theta} n^{v}
$$

where $z$ and $\epsilon$ denote aggregate and firm-specific (idiosyncratic) technology, respectively. 
The idiosyncratic technology process has autocorrelation $\rho_{I}$. It follows a Markov chain, whose transition matrix depends on the aggregate state of its time-varying standard deviation, $\sigma(\epsilon)$. In contrast, its support is independent of the aggregate state. To also capture observed excess kurtosis in the idiosyncratic productivity shocks, we use a mixture of two Gaussian distributions in the Tauchen-approximation algorithm instead of the usual normal distribution. ${ }^{16}$

We denote the trend growth rate of aggregate productivity by $(1-\theta)(\gamma-1)$, so that aggregate $y$ and $k$ grow at rate $\gamma-1$ along the balanced growth path. From now on we work with $k$ and $y$ (and later $C$ ) in efficiency units. The linearly detrended logarithm of aggregate productivity levels as well as linearly detrended $\sigma(\epsilon)$ evolve according to a VAR(1) process, with normal innovations $v$ that have zero mean and covariance $\Omega$ :

$$
\left(\begin{array}{c}
\log z^{\prime} \\
\sigma\left(\epsilon^{\prime}\right)-\bar{\sigma}(\epsilon)
\end{array}\right)=\varrho_{A}\left(\begin{array}{c}
\log z \\
\sigma(\epsilon)-\bar{\sigma}(\epsilon)
\end{array}\right)+\nu
$$

where $\bar{\sigma}(\epsilon)$ denotes the steady state standard deviation of idiosyncratic productivity innovations. $^{17}$

Productivity innovations at different aggregation levels are independent. Also, idiosyncratic productivity shocks are independent across productive units. In contrast, we do not impose any restrictions on $\Omega$ or $\varrho_{A} \in \mathbb{R}^{2 \times 2}$.

Each period a firms draws from a time-invariant distribution, $G$, its current cost of capital adjustment, $\xi \geq 0$, which is denominated in units of labor. $G$ is a uniform distribution on $[0, \bar{\xi}]$, common to all firms. Draws are independent across firms and over time, and employment is freely adjustable.

At the beginning of a period, a firm is characterized by its pre-determined capital stock, its idiosyncratic productivity, and its capital adjustment cost. Given this and the aggregate state, it decides its employment level, $n$, production and depreciation occurs, workers are paid, and investment decisions are made. Then the period ends.

Upon investment, $i$, the firm incurs a fixed cost of $\omega \xi$, where $\omega$ is the current real wage rate. Capital depreciates at rate $\delta$. We can then summarize the evolution of the firm's capital stock (in efficiency units) between two consecutive periods, from $k$ to $k^{\prime}$, as follows:

\begin{tabular}{lcc}
\hline \hline & Fixed cost paid & $\gamma k^{\prime}$ \\
\hline$i \neq 0:$ & $\omega \xi$ & $(1-\delta) k+i$ \\
\hline$i=0:$ & 0 & $(1-\delta) k$ \\
\hline
\end{tabular}

\footnotetext{
${ }^{16}$ Tauchen (1986). For details, see Section 4.

${ }^{17}$ Specifying this process in terms of $\log (\sigma(\epsilon))$, in order to avoid negativity of the standard deviation of idiosyncratic productivity shocks is - given its high steady state value and relatively low variability (see Bachmann and Bayer, 2009) - an unnecessary precaution that does not change the results.
} 
Given the i.i.d. nature of the adjustment costs, it is sufficient to describe differences across firms and their evolution by the distribution of firms over $(\epsilon, k)$. We denote this distribution by $\mu$. Thus, $(z, \sigma(\epsilon), \mu)$ constitutes the current aggregate state and $\mu$ evolves according to the law of motion $\mu^{\prime}=\Gamma(z, \sigma(\epsilon), \mu)$, which firms take as given.

Next we describe the dynamic programming problem of each firm. We will take two shortcuts (details can be found in Khan and Thomas, 2008). First, we state the problem in terms of utils of the representative household (rather than physical units), and denote by $p=p(z, \sigma(\epsilon), \mu)$ the marginal utility of consumption. Second, given the i.i.d. nature of the adjustment costs, continuation values can be expressed without explicitly taking into account future adjustment costs.

Let $V^{1}(\epsilon, k, \xi ; z, \sigma(\epsilon), \mu)$ denote the expected discounted value-in utils-of a firm that is in idiosyncratic state $(\epsilon, k, \xi)$, given the aggregate state $(z, \sigma(\epsilon), \mu)$. Then the expected value prior to the realization of the adjustment cost draw is given by:

$$
V^{0}(\epsilon, k ; z, \sigma(\epsilon), \mu)=\int_{0}^{\bar{\xi}} V^{1}(\epsilon, k, \xi ; z, \sigma(\epsilon), \mu) G(d \xi) .
$$

With this notation the dynamic programming problem is given by:

$$
V^{1}(\epsilon, k, \xi ; z, \sigma(\epsilon), \mu)=\max _{n}\left\{\mathrm{CF}+\max \left(V_{\mathrm{no} \mathrm{adj}}, \max _{k^{\prime}}\left[-\mathrm{AC}+V_{\mathrm{adj}}\right]\right)\right\}
$$

where CF denotes the firm's flow value, $V_{\text {no adj }}$ the firm's continuation value if it chooses inaction and does not adjust, and $V_{\text {adj }}$ the continuation value, net of adjustment costs $A C$, if the firm adjusts its capital stock. That is:

$$
\begin{aligned}
\mathrm{CF} & =\left[z \epsilon k^{\theta} n^{v}-\omega(z, \sigma(\epsilon), \mu) n\right] p(z, \sigma(\epsilon), \mu), \\
V_{\text {no adj }} & =\beta \mathrm{E}\left[V^{0}\left(\epsilon^{\prime},(1-\delta) k / \gamma ; z^{\prime}, \sigma\left(\epsilon^{\prime}\right), \mu^{\prime}\right)\right], \\
A C & =\xi \omega(z, \sigma(\epsilon), \mu) p(z, \sigma(\epsilon), \mu), \\
V_{\mathrm{adj}} & =-i p(z, \sigma(\epsilon), \mu)+\beta \mathrm{E}\left[V^{0}\left(\epsilon^{\prime}, k^{\prime} ; z^{\prime}, \sigma\left(\epsilon^{\prime}\right), \mu^{\prime}\right)\right],
\end{aligned}
$$

where both expectation operators average over next period's realizations of the aggregate and idiosyncratic productivity states, conditional on this period's values, and we recall that $i=\gamma k^{\prime}-$ $(1-\delta) k$. Also, $\beta$ denotes the discount factor of the representative household.

Taking as given prices $\omega(z, \sigma(\epsilon), \mu)$ and $p(z, \sigma(\epsilon), \mu)$, and the law of motion $\mu^{\prime}=\Gamma(z, \sigma(\epsilon), \mu)$, the firm chooses optimally labor demand, whether to adjust its capital stock at the end of the period, and the optimal capital stock, conditional on adjustment. This leads to policy functions: $N=N(\epsilon, k ; z, \sigma(\epsilon), \mu)$ and $K=K(\epsilon, k, \xi ; z, \sigma(\epsilon), \mu)$. Since capital is pre-determined, the optimal employment decision is independent of the current adjustment cost draw. 


\subsection{Households}

We assume a continuum of identical households that have access to a complete set of statecontingent claims. Hence, there is no heterogeneity across households. Moreover, they own shares in the firms and are paid dividends. We do not need to model the household side in detail (see Khan and Thomas (2008) for the details), and concentrate instead on the first-order conditions to determine the equilibrium wage and the marginal utility of consumption.

Households have a standard felicity function in consumption and (indivisible) labor:

$$
U\left(C, N^{h}\right)=\log C-A N^{h}
$$

where $C$ denotes consumption and $N^{h}$ the household's labor supply. Households maximize the expected present discounted value of the above felicity function. By definition we have:

$$
p(z, \sigma(\epsilon), \mu) \equiv U_{C}\left(C, N^{h}\right)=\frac{1}{C(z, \sigma(\epsilon), \mu)},
$$

and from the intratemporal first-order condition:

$$
\omega(z, \sigma(\epsilon), \mu)=-\frac{U_{N}\left(C, N^{h}\right)}{p(z, \sigma(\epsilon), \mu)}=\frac{A}{p(z, \sigma(\epsilon), \mu)} .
$$

\subsection{Recursive Equilibrium}

A recursive competitive equilibrium for this economy is a set of functions

$$
\left(\omega, p, V^{1}, N, K, C, N^{h}, \Gamma\right)
$$

that satisfy

1. Firm optimality: Taking $\omega, p$ and $\Gamma$ as given, $V^{1}(\epsilon, k ; z, \sigma(\epsilon), \mu)$ solves (4) and the corresponding policy functions are $N(\epsilon, k ; z, \sigma(\epsilon), \mu)$ and $K(\epsilon, k, \xi ; z, \sigma(\epsilon), \mu)$.

2. Household optimality: Taking $\omega$ and $p$ as given, the household's consumption and labor supply satisfy (7) and (8).

3. Commodity market clearing:

$$
C(z, \sigma(\epsilon), \mu)=\int z \epsilon k^{\theta} N(\epsilon, k ; z, \sigma(\epsilon), \mu)^{v} d \mu-\iint_{0}^{\bar{\xi}}[\gamma K(\epsilon, k, \xi ; z, \sigma(\epsilon), \mu)-(1-\delta) k] d G d \mu .
$$




\section{Labor market clearing:}

$$
N^{h}(z, \sigma(\epsilon), \mu)=\int N(\epsilon, k ; z, \sigma(\epsilon), \mu) d \mu+\iint_{0}^{\bar{\xi}} \xi \mathscr{J}(\gamma K(\epsilon, k, \xi ; z, \sigma(\epsilon), \mu)-(1-\delta) k) d G d \mu
$$

where $\mathscr{J}(x)=0$, if $x=0$ and 1 , otherwise.

5. Model consistent dynamics: The evolution of the cross-section that characterizes the economy, $\mu^{\prime}=\Gamma(z, \sigma(\epsilon), \mu)$, is induced by $K(\epsilon, k, \xi ; z, \sigma(\epsilon), \mu)$ and the exogenous processes for $z$, $\sigma(\epsilon)$ as well as $\epsilon$.

Conditions 1, 2, 3 and 4 define an equilibrium given $\Gamma$, while step 5 specifies the equilibrium condition for $\Gamma$.

\subsection{Solution}

As is well-known, (4) is not computable, since $\mu$ is infinite dimensional. Hence, we follow Krusell and Smith $(1997,1998)$ and approximate the distribution $\mu$ by its first moment over capital, and its evolution, $\Gamma$, by a simple log-linear rule. In the same vein, we approximate the equilibrium pricing function by a log-linear rule, discrete aggregate state by discrete aggregate state:

$$
\begin{aligned}
& \log \bar{k}^{\prime}=a_{k}(z, \sigma(\epsilon))+b_{k}(z, \sigma(\epsilon)) \log \bar{k}, \\
& \log p=a_{p}(z, \sigma(\epsilon))+b_{p}(z, \sigma(\epsilon)) \log \bar{k},
\end{aligned}
$$

where $\bar{k}$ denotes aggregate capital holdings. Given (8), we do not have to specify an equilibrium rule for the real wage. As usual with this procedure, we posit this form and check that in equilibrium it yields a good fit to the actual law of motion. In contrast to models without second moment shocks, where it has been extensively shown that the first moment suffices, we show here that the pure $R^{2}$ goodness-of-fit metric does not perform as well anymore: $R^{2}$ below 0.9 are possible, as we shall see in Section 5.2. Nevertheless, Bachmann and Bayer (2009) show that the aggregate dynamics of such an economy are hardly affected, when higher moments of the capital distribution are included and the $R^{2}$ are pushed closer to unity (see Bachmann et al. (2008) for a similar observation). We show here that also the cross-sectional dynamics are affected only to a small degree. And since we consistently find that not including higher moments leads to a slight underestimation of the procyclicality of investment dispersion, we prefer the increase in computational speed and report our results, unless otherwise noted, with the first moment only as a state variable. 
Combining these assumptions and substituting $\bar{k}$ for $\mu$ into (4) and using (9a)-(9b), we have that (4) becomes a computable dynamic programming problem with policy functions $N=N(\epsilon, k ; z, \sigma(\epsilon), \bar{k})$ and $K=K(\epsilon, k, \xi ; z, \sigma(\epsilon), \bar{k})$. We solve this problem via value function iteration on $V^{0}$.

With these policy functions, we can then simulate a model economy without imposing the equilibrium pricing rule (9b), but rather solve for it along the way. We simulate the model economy for 1,600 time periods and discard the first 100 observations, when computing any statistics. This procedure generates a time series of $\left\{p_{t}\right\}$ and $\left\{\bar{k}_{t}\right\}$ endogenously, with which assumed rules (9a)-(9b) can be updated via a simple OLS regression. The procedure stops when the updated coefficients $a_{k}(z, \sigma(\epsilon))$ and $b_{k}(z, \sigma(\epsilon))$, as well as $a_{p}(z, \sigma(\epsilon))$ and $b_{p}(z, \sigma(\epsilon))$ are sufficiently close to the previous ones. We skip the details of this procedure, as this has been outlined elsewhere - see Khan and Thomas (2008) and Bachmann et al. (2008).

\section{Calibration}

The model period is a year - in congruence with the data frequency in USTAN. The following parameters have standard values: $\beta=0.98$ and $\delta=0.094$, which we compute from German national accounting data for the sectoral aggregate that the USTAN sample corresponds to: the non-financial private business sector. Given this depreciation rate, we pick $\gamma=1.014$, in order to match the time-average aggregate investment rate of 0.108 . This number is also consistent with German long-run growth rates. The log-felicity function features an elasticity of intertemporal substitution (EIS) of one. The disutility of work parameter, $A$, is chosen to generate an average time spent at work of 0.33: $A=2$ for the baseline calibration.

We set the output elasticities of labor and capital to $v=0.5565$ and $\theta=0.2075$, respectively, which correspond to the measured median labor and capital shares in manufacturing in the USTAN data base (see Appendix A.4). While our data also include a considerable amount of firms from other sectors, any weighted average or median of these shares would still be close to the manufacturing values, which is why we decided to use them in our baseline calibration. We discuss robustness to this parameter choice in Section 5.1 and Appendix A.4. ${ }^{18}$

Next, we have to choose the parameters of the two-state aggregate shock process. Here we

\footnotetext{
${ }^{18}$ If one views the DRTS assumption as a mere stand-in for a CRTS production function with monopolistic competition, than these choices would correspond to an employment elasticity of the underlying production function of 0.7284 and a markup of $\frac{1}{\theta+v}=1.31$. Given the regulated product markets in Germany, this is a reasonable value. The implied capital elasticity of the revenue function, $\frac{\theta}{1-v}$ is 0.47 . Finally, model simulations show that using the capital share as an estimate for the output elasticity of capital under the null hypothesis of the model leads to a small overestimation of the latter, which, as we will show in Section 5.1, leads to the the baseline calibration being conservative relative to the main result: procyclicality of investment dispersion.
} 
simply estimate a bivariate, unrestricted VAR with the linearly detrended natural logarithm of the aggregate Solow residual ${ }^{19}$ and the linearly detrended $\sigma(\epsilon)$-process from the USTAN data. ${ }^{20}$ The parameters of this VAR are as follows: ${ }^{21}$

$$
\varrho_{A}=\left(\begin{array}{cc}
0.3144 & -2.3775 \\
0.051 & 0.7794
\end{array}\right) \quad \Omega=\left(\begin{array}{cc}
0.0176 & -0.5773 \\
-0.5773 & 0.0027
\end{array}\right)
$$

This process is discretized on a [5×5]-grid, using a bivariate analog of Tauchen's procedure.

We measure the steady state standard deviation of idiosyncratic technology innovations as $\bar{\sigma}(\epsilon)=0.1201$. Since these innovations also exhibit mild excess kurtosis -4.4480 on average over our time horizon,$-{ }^{22}$ and since the adjustment cost parameter $\bar{\xi}$ will be identified by the kurtosis of the firm-level investment rate (in addition to its skewness), we want to avoid attributing excess kurtosis in the firm-level investment rate to nonlinearities in the adjustment technology, when the driving force itself has kurtosis. Hence, we incorporate the measured excess kurtosis into the discretization process for the idiosyncratic technology state. ${ }^{23}$ Finally, we set $\rho_{I}=0.95$, in accordance with the high persistence of Solow residual innovations we find in the data. This process is discretized on a 19-state-grid, using Tauchen's procedure with mixed Gaussian normals. $^{24}$

Given the aforementioned set of parameters $\left(\beta, \delta, \gamma, A, v, \theta, \varrho_{A}, \Omega, \bar{\sigma}(\epsilon), \rho_{I}\right)$, we then calibrate the adjustment costs parameter $\bar{\xi}$ to minimize a quadratic form in the logarithmic differences between the time-average firm-level investment rate skewness produced by the model and the data, as well as the time-average firm-level investment rate kurtosis:

$$
\begin{aligned}
\min _{\bar{\xi}} \Psi(\bar{\xi}) \equiv 0.5 \cdot\left[\left(\log \left(\frac{1}{26} \sum_{t} \operatorname{skewness}\left(\frac{i_{i, t}}{0.5 *\left(k_{i, t}+k_{i, t+1}\right)}\right)(\bar{\xi})-1.6645\right)\right)^{2}+\right. \\
\left.\left(\log \left(\frac{1}{26} \sum_{t} \operatorname{kurtosis}\left(\frac{i_{i, t}}{0.5 *\left(k_{i, t}+k_{i, t+1}\right)}\right)(\bar{\xi})-19.1046\right)\right)^{2}\right] .
\end{aligned}
$$

As can be seen from (11), the distribution of firm-level investment rates exhibits both substantial positive skewness - 1.6645 - as well as excess kurtosis - 19.1046. Caballero et al. (1995) document a similar fact for U.S. manufacturing plants. They also argue that non-convex capital

\footnotetext{
${ }^{19}$ We use again $v=0.5565$ and $\theta=0.2075$ in these calculations.

${ }^{20}$ After firm-level and sectoral fixed effects have been removed.

${ }^{21}$ With a slight abuse of notation, but for the sake of readability, $\Omega$ displays standard deviations on the main diagonal and correlations on the off diagonal.

${ }^{22}$ We find no skewness.

${ }^{23}$ We achieve this by using a mixture of two Gaussian distributions: $N(0,0.0777)$ and $N(0,0.1625)$ - the standard deviations are $0.1201 \pm 0.0424$ - with a weight of 0.4118 on the first distribution.

${ }^{24}$ The cross-sectional results do not change significantly with either an increase in the fineness of the aggregate grid to $[9 \times 9]$, nor with one in the idiosyncratic grid to a 35 -state-grid.
} 
adjustment costs are an important ingredient to explain such a strongly non-Gaussian distribution, given a close-to-Gaussian shock process. We therefore use the deviation from Gaussianity in firm-level investment rates to identify $\bar{\xi}$.

The following Table 9 demonstrates identification of $\bar{\xi}$, as cross-sectional skewness and kurtosis of the firm-level investment rates are both monotonically increasing in $\bar{\xi}$. The minimum of the distance measure $\Psi$ is achieved for $\bar{\xi}=0.25$, our baseline case. ${ }^{25}$ This implies costs conditional on adjustment equivalent to $13.3 \%$ of annual firm-level output on average, which is well in line with estimates from the U.S. (see Bloom, 2009). A description of the aggregate dynamics of the baseline calibration is relegated to Appendix C.

Table 9: CAlibration of Adjustment Costs $-\bar{\xi}$

\begin{tabular}{lcccc}
\hline $\bar{\xi}$ & Skewness & Kurtosis & $\Psi(\bar{\xi})$ & $\begin{array}{c}\text { Adj. costs/ } \\
\text { Unit of Output }\end{array}$ \\
\hline 0.01 & 0.7851 & 5.0429 & 1.0814 & $1.5 \%$ \\
0.05 & 1.5171 & 7.6509 & 0.6504 & $4.2 \%$ \\
0.10 & 1.9350 & 9.3411 & 0.5170 & $6.8 \%$ \\
$0.25(\mathrm{BL})$ & 2.5623 & 12.1704 & 0.4413 & $13.3 \%$ \\
0.5 & 3.0723 & 14.7831 & 0.4698 & $23.3 \%$ \\
1 & 3.5970 & 17.8299 & 0.5471 & $43.2 \%$ \\
\hline
\end{tabular}

${ }^{25}$ We searched over a much finer grid of $\bar{\xi}$ than displayed in the table, in order to find the optimal $\bar{\xi}$. 


\section{Results}

\subsection{Baseline Results}

Can a thus calibrated DSGE model with idiosyncratic productivity shocks, fixed adjustment costs to capital and countercyclical innovations to the dispersion of firm-level Solow residuals reproduce the cyclicality of the cross-sectional dynamics observed in the data?

Figure 2: Cross-sectional Dispersion of Firm-Level Investment Rates and Solow Residual Innovations

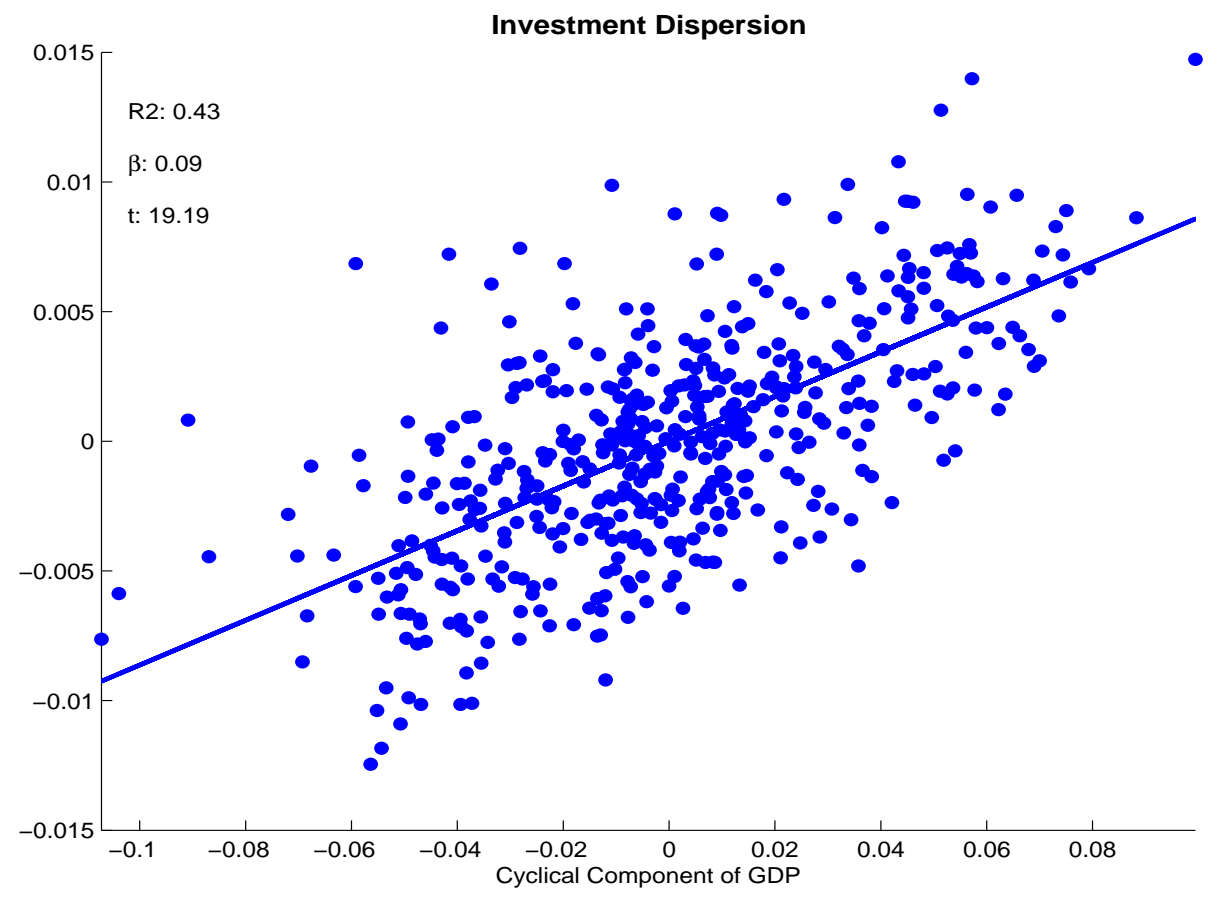

Notes: Dispersion refers to the cross sectional standard-deviation.

Figure 2 shows that indeed the model produces procyclical investment dispersion close to the one found in the data and shown in Figure 1 in the introduction. Likewise, Figure 7 in Appendix A.5 shows a simulated time path of investment dispersion that clearly exhibits positive comovement with aggregate output. We use HP(100)-filtered aggregate model output as our cyclical measure. Table 10 summarizes our main result numerically: in our baseline calibration the model matches the procyclicality of firm-level investment rate dispersion almost exactly, even though it was calibrated to the steady state Non-Gaussianity of the investment rate distribution. ${ }^{26}$ The countercyclical dispersions of value added and employment changes are captured at least to a large extent.

\footnotetext{
${ }^{26}$ These numbers are obtained from a simulation of $T=1500$. Using an even longer simulation of $T=3000$ and
} 
Table 10: Cyclicality of Cross-Sectional Dispersion - Baseline Model

\begin{tabular}{lcc}
\hline \hline Cross-sectional Moment & Data & Model \\
\hline$\sigma\left(\frac{i_{i, t}}{0.5 *\left(k_{i, t}+k_{i, t+1}\right)}\right)$ & 0.613 & 0.652 \\
$\sigma\left(\Delta \log y_{i, t}\right)$ & -0.450 & -0.287 \\
$\sigma\left(\frac{\Delta n_{i, t+1}}{0.5 *\left(n_{i, t}+n_{i, t+1}\right)}\right)$ & -0.498 & -0.292 \\
\hline
\end{tabular}

Notes: Correlation coefficients between HP(100)-filtered output and a cross-sectional standard deviation. The column 'Model' refers to the correlation coefficients from a simulation of the model over $T=1500$ periods.

The next Table 11 illustrates how lumpy capital adjustment and countercyclical second moment shocks interact to generate the procyclicality result.

Table 11: Adjustment Costs And Cyclicality of Investment Dispersion

\begin{tabular}{lcc}
\hline \hline $\bar{\xi}$ & Full Model w. 2nd moment shocks & Model w/o. 2nd moment shocks \\
\hline 0 & -0.3845 & - \\
0.06 (skewness only) & 0.2232 & 0.8556 \\
0.10 & 0.3795 & 0.8611 \\
$0.25(\mathrm{BL})$ & 0.6517 & 0.8740 \\
0.5 & 0.7913 & 0.8834 \\
1 & 0.8738 & 0.8958 \\
\hline
\end{tabular}

Notes: See notes to Table 10. Note that for the case with $\bar{\xi}=0$ and no second-moment shocks any time series variation of $\sigma\left(\frac{i_{i, t}}{0.5\left(k_{i, t}+k_{i, t+1}\right)}\right)$ is a numerical artifact, which means that its correlation coefficient with output is not defined. $\varrho_{A}=0.5259$ and $\Omega=0.0182$ for the univariate case.

Two findings are important: in the presence of countercyclical second moment shocks, the procyclicality of investment dispersion is a gradually and monotonically increasing function of the adjustment cost parameter. What is perhaps surprising is that the level of adjustment costs that best matches the cross-sectional average skewness and kurtosis of firm-level investment rates - two statistics that have been known to be related to the level of nonconvexities at the micro-level (see Caballero et al., 1995) - also leads to the model matching almost exactly an important time series moment of the cross-sectional business cycle dynamics. The table also shows that a more conservative calibration that calibrates to the cross-sectional skewness of firm-level investment rates only and puts zero weight on their kurtosis, still generates a sizeable level of procyclicality in investment dispersion, given that the frictionless case, unsurprisingly, merely replicates the countercyclicality of the dispersion of the driving force.

breaking it up into 60 pieces of $T=26$ (the length of the USTAN sample) independent time series produces an average value of 0.700 for the correlation between investment rate dispersion and cyclical output with a standard deviation of: 0.106 . The range is $[0.423,0.861]$. 
Moreover, the second column of this table shows that without second moment shocks, a minimal level of non-convexity immediately generates procyclicality in investment dispersion, as shown in the introduction. But it also makes the model overshoot this number considerably. Thus, countercyclical second moment shocks are an important part in understanding crosssectional firm dynamics, both in generating countercyclical dispersions of value and employment changes, but also to generate realistic procyclicality in investment dispersion. Without them, it would simply be too easy to generate the latter. We view this as an important confirmation of our calibration and our mechanism: in the presence of quantitatively realistic countercyclicality of the dispersion of the driving force, it is exactly that level of adjustment costs that matches best the nonlinear average moments of the investment rate distribution that also generates just the right correlation coefficient between the standard deviation of investment rates and aggregate output. Table 11 shows that this identification is rather tight.

Table 12 illustrates how the procyclicality of the investment dispersion relates to the procyclicality of the extensive margin - the mechanism sketched in the introduction - and how the latter and the curvature of the revenue function in capital interact to generate the procyclicality result.

Table 12: FACtor Elasticities AND CyCliCALity of InVESTMENT DisPERSion

\begin{tabular}{lccc}
\hline \hline Cross-sectional Moment & Baseline $(0.47)$ & Rev. Ela. $=0.57$ & Rev. Ela.=0.63 \\
\hline$\sigma\left(\frac{i_{i, t}}{0.5 *\left(k_{i, t}+k_{i, t+1}\right)}\right)$ & 0.6517 & 0.1745 & -0.3267 \\
Fraction of Adjusters & 0.6413 & -0.0549 & -0.4686 \\
\hline
\end{tabular}

Notes: See notes to Table 10. 'Rev. Ela.' stands for the revenue elasticity of capital in a reduced form revenue function, after labor has been maximized out. It is given by $\frac{\theta}{1-v}$.

The results in columns two and three refer to setups with factor elasticities $v=0.5333, \theta=$ 0.2667 and $v=0.5556, \theta=0.2778$, respectively, compared to $v=0.5565, \theta=0.2075$ in the baseline scenario. $^{27}$ It is clear that larger revenue elasticities in capital after labor has been maximized out, imply a lower procyclicality of the extensive margin and thus for the investment rate dispersion. Smaller revenue elasticities or higher curvature of the production function imply that the intensive margin of investment becomes less flexible: the range of the optimal capital return level in the baseline scenario is [0.0247,41.0759], for the second column $[0.0162,102.0587]$ and $[0.0065,178.6259]$ for the third column; all with the same process for idiosyncratic technology. To achieve the optimal path for aggregate investment, the extensive

\footnotetext{
${ }^{27}$ In a monopolistic competition framework, column two implies a scenario with a CRTS-one-third-two-third production function and a markup of 1.25, column three a markup of 1.20. In each case, we recompute firm-level and aggregate Solow residuals, estimate a new driving process (2) and re-calibrate the adjustment cost parameter $\bar{\xi}$ to minimize $\Psi(\bar{\xi})$ in $(11)$.
} 
margin becomes more important for the firms, the higher the curvature of the revenue function. This effect of curvature is well known and explained in detail in Gourio and Kashyap (2007).

Table 13 shows the effect of general equilibrium on both the procyclicality of the extensive margin as well as the procyclicality of investment dispersion. Real wage and interest rate movements lead to stronger aggregate coordination and therefore to a higher procyclicality of the fraction of adjusters, which in turn increases the cyclical comovement of both the first moment of the investment rate distribution - from 0.3602 to 0.9321 - as well as the second moment, as can be seen in the following table. We thus confirm the conjecture in Khan and Thomas (2005) that general equilibrium price movements are important to quantitatively account for crosssectional business cycle dynamics.

Table 13: Cyclicality of Investment Dispersion and General EQUilibrium

\begin{tabular}{lcc}
\hline \hline Cross-sectional Moment & Baseline - GE & PE \\
\hline$\sigma\left(\frac{i_{i, t}}{0.5 *\left(k_{i, t}+k_{i, t+1}\right)}\right)$ & 0.6517 & 0.3134 \\
Fraction of Adjusters & 0.6413 & 0.4736 \\
\hline
\end{tabular}

Notes: See notes to Table 10. 'GE' stands for general equilibrium and means a model simulation with market clearing wages and interest rates. 'PE' stands for partial equilibrium and means a model simulation, where wages and interest rates are held constant at the average level in the 'GE'-simulation.

To sum up, the extent of both, the procyclicality of investment dispersion as well as the countercyclicality of the dispersion of firm-level Solow residual innovations, impose important and very tight restrictions on important structural parameters, such as adjustment frictions and factor elasticities in the production function. More generally, this makes the study of crosssectional business cycle dynamics important for the structure and calibration of heterogenousfirm models. We also confirm the conjecture in Khan and Thomas (2005) that general equilibrium price movements are important to quantitatively account for the cross-sectional business cycle dynamics observed in the data.

\subsection{Robustness}

In the following Table 14 we document robustness of our baseline result to some of the parameter choices we have made in the baseline calibration. We change one parameter at a time, but do not re-calibrate $\bar{\xi}$.

In the second row of Table 14, we check whether the introduction of a firm-level process for Solow residual innovations with quantitatively realistic excess kurtosis drives our result and the answer is negative. In order to check robustness of our results to a potential underestimation 
Table 14: Procyclicality of InVEstment Dispersion - Robustness

\begin{tabular}{lc}
\hline \hline Scenario & $\rho\left(\sigma\left(\frac{i_{i, t}}{0.5 *\left(k_{i, t}+k_{i, t+1}\right)}\right), H P(100)-Y\right)$ \\
\hline Baseline & 0.6517 \\
\hline No excess kurtosis & 0.5755 \\
Higher volatility of $\sigma\left(\Delta \epsilon_{i, t}\right)$ & 0.1368 \\
Lower $\bar{\sigma}(\epsilon)$ & 0.9282 \\
Lower volatility of $z_{t}$ & 0.4085 \\
$C R R A=3$ & 0.5855 \\
Timing of $\sigma\left(\Delta \epsilon_{i, t}\right)$ & 0.5182 \\
$\operatorname{mean}\left(\Delta \epsilon_{i, t}\right)$ & 0.7572 \\
\hline
\end{tabular}

Notes: See notes to Table 10.

of the volatility of the countercyclical second-moment shock, we double it, while keeping its steady state value fixed at $\bar{\sigma}(\epsilon)=0.1201$. We implement this by doubling the deviations from a linear trend in the $\sigma(\epsilon)$-process and re-estimating the unrestricted bivariate VAR between it and the linearly detrended aggregate Solow residual. ${ }^{28}$ As expected, in this case the ability of the procyclical extensive margin effect to overcome the countercyclical second-moment shocks is limited, because the latter fluctuates more. This drives down the correlation of the investment rate dispersion and the cyclical component of aggregate output to 0.1368 . Notice, however, that it is still positive, non-convexities in capital adjustment still cause a procyclical extensive margin effect that partially offsets the countercyclical second-moment shocks. But it is also clear from this exercise that the strongly procyclical investment dispersion that we find in the data 0.613 - is at odds with the even more volatile countercyclical second-moment shocks proposed in Bloom (2009) and Bloom et al. (2009) as important drivers of the business cycle. Halving the steady state $\bar{\sigma}(\epsilon)$ - see the fourth row -, in contrast, improves ceteris paribus the ability of the model to generate procyclical investment dispersion. This scenario is relevant, if one were to attribute some part of the measured $\bar{\sigma}(\epsilon)$ to measurement error in firm-level Solow residuals. The fifth row displays a scenario, where we lower the volatility of the first-moment shock so that the model now matches the volatility of the cyclical component of output, which in the baseline calibration is too high (see Appendix $\mathrm{C}$ for a discussion). This amounts effectively to a lowering of the relative importance of first-moment shocks versus second-moment shocks, and it is important to make sure that our result is not driven by measurement error and too high a volatility in the aggregate Solow residual. Table 14 shows that this is not the case with the correlation of investment dispersion and the cyclical component of aggregate output still

\footnotetext{
${ }^{28}$ The unconditional time-series percentage standard deviation of $\sigma(\epsilon)$ is $2.67 \%$ in the baseline case. We double that.
} 
being 0.4085 . Nevertheless, the procyclicality of investment dispersion is reduced, as secondmoment shocks have effectively become more important. Next, we check whether our unity CRRA is driving our result by increasing the CRRA to 3 . This leads to hardly any change. ${ }^{29}$ Furthermore, we check whether the result is sensitive to the timing assumption about the revelation of the dispersion of the firm-level Solow residual innovation. The baseline model assumes that $\sigma\left(\Delta \epsilon_{i, t}\right)$ is revealed today, concomitantly with $z_{t}$ and $\epsilon_{t}$, aggregate and idiosyncratic technology, and that both $z_{t}$ and $\sigma\left(\Delta \epsilon_{i, t}\right)$ predict the dispersion of the firm-level Solow residual innovation tomorrow through persistence in the VAR (10). There is another plausible timing assumption: $\sigma\left(\Delta \epsilon_{i, t+1}\right)$ is revealed today, which means investors know about the actual productivity risk tomorrow at the time of the investment decision. As the next to last row shows, this lowers somewhat the procyclicality of investment dispersion, but the extensive margin effect is still sizeable, as the corresponding number from a frictionless model would be -0.5432 , compared to the -0.3845 in the frictionless counterpart of the baseline timing assumption. Finally, we replace the aggregate Solow residual with the average firm-level Solow residual from USTAN in the bivariate aggregate driving force, which somewhat increases the procyclicality of investment dispersion.

\section{Higher Moments in the Krusell and Smith Rules}

It remains to be shown that our result is not driven by the choice of only the average capital stock in the Krusell and Smith rules (9a) and (9b). While it is the case that in the presence of countercyclical second-moment shocks the conventional $R^{2}$-measure is fairly low - at least in some combinations of the discrete aggregate states, the minimum is $0.8071-$, and while it is also true that including the skewness of the capital distribution ${ }^{30}$ leads to an average increase of the $R^{2}$ for the capital regressions from 0.9267 to 0.9925 and for the marginal utility of consumption regressions from 0.9974 to 0.9998, neither the aggregate behavior (see Bachmann and Bayer (2009) for details) nor the cross-sectional dynamics of the model are significantly altered: the correlation between investment dispersion and cyclical aggregate output raises slightly from 0.6517 to 0.7187 . That means, if anything, our baseline numerical specification is somewhat conservative with respect to our main finding. The bottom line, however, is that better forecasts do not necessarily induce the agents to behave differently (see Bachmann et al. (2008) for a similar finding).

The scatter plots in Figure 3 make this point graphically: the positive relationship between investment dispersion and cyclical aggregate output is nearly indistinguishable between a nu-

\footnotetext{
${ }^{29}$ Technically, with the separable felicity specification in (6) there is no balanced growth path with CRRA=3. The model remains consistent with balanced growth, if the disutility of leisure grows with the steady state growth rate, $\gamma$, and the fundamental discount rate is accordingly adjusted.

${ }^{30}$ Including the standard deviation of capital does not yield any significant improvements in $R^{2}$. The average $R^{2}$ over all discrete states for the skewness regression, that is analogous to (9a), is 0.9703 .
} 
Figure 3: Cross-sectional Dispersion of Firm-Level Investment Rates and Solow Residual Innovations: Higher Moments
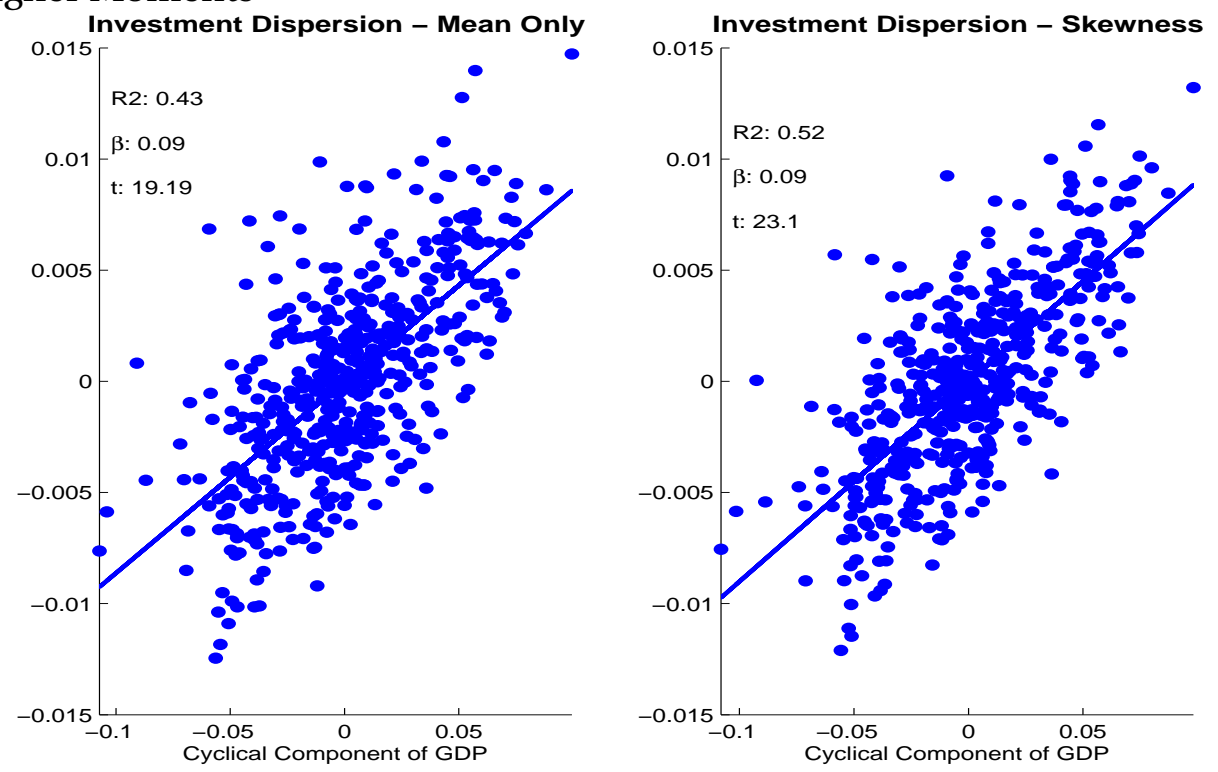

Notes: Dispersion refers to the cross sectional standard-deviation.

merical specification where only average capital is used as a state variable and one, where also the skewness of firm-level capital is included in the forecasting rules.

\section{Final Remarks}

This paper, to the best of our knowledge, is the first to study the cyclical behavior of the second moments of the cross-sections of firm-level innovations to value added, Solow residuals, capital and employment. We show that even in the presence of countercyclically disperse Solow residual innovations the dispersion of investment rates is significantly and robustly procyclical. We also show that this can be quantitatively explained by realistically calibrated non-convex adjustment costs: a procyclical extensive margin effect dominates the countercyclical dispersion in the driving force. Other potential explanations, such as financial frictions, are ruled out. We finally argue that the understanding of the cross-sectional business cycle dynamics imposes important restrictions on structural parameters and driving forces. In particular, large countercyclical second moment shocks that could generate sizeable business cycle dynamics would be incompatible with procyclical investment dispersion.

We view this as just the beginning of a new research program that attempts to understand more comprehensively the time-series behavior of the entire cross-section of firms, not merely the cyclicality of second moments. This will ultimately lead to a better microfoundation of structural heterogeneous-firm models and contribute to making them suitable for policy analysis. We also plan to corroborate these new findings for more countries, in particular the U.S. 


\section{References}

[1] Bachmann, R. and C. Bayer (2009). "Firm-specific Productivity Risk over the Business Cycle: Facts and Aggregate Implications”, mimeo.

[2] Bachmann, R., Caballero, R. and E. Engel (2008). "Aggregate Implications of Lumpy Investment: New Evidence and a DSGE Model", mimeo.

[3] Bloom, N. (2009). “The Impact of Uncertainty Shocks”, Econometrica, forthcoming.

[4] Bloom, N., M. Floetotto and N. Jaimovich (2009). "Really Uncertain Business Cycles", mimeo.

[5] Caballero, R., E. Engel and J. Haltiwanger (1995). "Plant-Level Adjustment and Aggregate Investment Dynamics”, Brookings Paper on Economic Activity, 1995, (2), 1-54.

[6] Caplin, A. and D. Spulber (1987). "Menu Costs and the Neutrality of Money", Quarterly Journal of Economics, 102, 703-726.

[7] Cooper, R. and J. Haltiwanger (2006). “On the Nature of Capital Adjustment Costs”, Review of Economic Studies, 73, 611-633.

[8] Davis, S., J. Haltiwanger and S. Schuh (1996). "Job Creation and Destruction", Cambridge, MA: MIT Press.

[9] Davis, S., J. Haltiwanger, R. Jarmin and J. Miranda (2006). "Volatility and Dispersion in Business Growth Rates: Publicly Traded and Privately Held Firms”, NBER Macroeconomics Annual.

[10] Doepke, J. and S. Weber (2006). “The Within-Distribution Business Cycle Dynamics of German Firms", Discussion Paper Series 1: Economic Studies, No 29/2006. Deutsche Bundesbank.

[11] Doepke, J., M. Funke, S. Holly and S. Weber (2005). "The Cross-Sectional Dynamics of German Business Cycles: a Bird's Eye View", Discussion Paper Series 1: Economic Studies, No 23/2005. Deutsche Bundesbank.

[12] Doepke, J., M. Funke, S. Holly and S. Weber (2008). “The Cross-Section of Output and Inflation in a Dynamic Stochastic General Equilibrium Model with Sticky Prices", CWPE 0853. 
[13] Eisfeldt, A. and A. Rampini (2006). "Capital Reallocation and Liquidity", Journal of Monetary Economics, 53, 369-399.

[14] Gourio, F. and A.K. Kashyap, (2007). "Investment Spikes: New Facts and a General Equilibrium Exploration”, Journal of Monetary Economics, 54, 2007, 1-22.

[15] Higson, C., S. Holly and P. Kattuman (2002). "The Cross-Sectional Dynamics of the US Business Cycle: 1950-1999”, Journal of Economic Dynamics and Control, 26, 1539-1555.

[16] Higson, C., S. Holly, P. Kattuman and S. Platis (2004): "The Business Cycle, Macroeconomic Shocks and the Cross Section: The Growth of UK Quoted Companies", Economica, 71/281, May 2004, 299-318.

[17] Holly, S. and E. Santoro (2008). "Financial Fragility, Heterogeneous Firms and the CrossSection of the Business Cycle", CWPE 0846.

[18] von Kalckreuth, U. (2003). "Exploring the role of uncertainty for corporate investment decisions in Germany", Swiss Journal of Economics, Vol. 139(2), 173-206.

[19] Khan, A. and J. Thomas, (2005). "Idiosyncratic Shocks and the Role of Nonconvexities in Plant and Aggregate Investment Dynamics”, Federal Reserve Bank of Minneapolis - WP.

[20] Khan, A. and J. Thomas, (2008). "Idiosyncratic Shocks and the Role of Nonconvexities in Plant and Aggregate Investment Dynamics”, Econometrica, 76(2), March 2008, 395-436.

[21] Krusell, P. and A. Smith (1997). "Income and Wealth Heterogeneity, Portfolio Choice and Equilibrium Asset Returns”, Macroeconomic Dynamics 1, 387-422.

[22] Krusell, P. and A. Smith (1998). "Income and Wealth Heterogeneity in the Macroeconomy", Journal of Political Economy, 106 (5), 867-896.

[23] Ravn, M. and H. Uhlig (2002). "On Adjusting the Hodrick-Prescott Filter for the Frequency of Observations”, The Review of Economics and Statistics, 84 (2), 371-380.

[24] Stoess, E. (2001). "Deutsche Bundesbank's Corporate Balance Sheet Statistics and Areas of Application", Schmollers Jahrbuch: Zeitschrift fuer Wirtschafts- und Sozialwissenschaften (Journal of Applied Social Science Studies), 121, 131-137

[25] Tauchen, G. (1986). "Finite State Markov-Chain Approximations To Univariate and Vector Autoregressions”, Economics Letters 20, 177-181. 


\section{A Appendix A - Data Appendix}

\section{A.1 Description of the Sample}

The Bundesbank's corporate balance sheet database (Unternehmensbilanzstatistik, USTAN henceforth) has been originally created as a by-product of the bank's rediscounting activities, an important instrument of monetary policy before the introduction of the Euro. When a commercial bank wished to pledge a commercial bill of exchange to the Bundesbank, the commercial bank had to prove the creditworthiness of the bill. For that purpose the bank had to provide the Bundesbank with balance sheet information of all parties who backed the bill of exchange. By law, the Bundesbank could only accept bills backed by at least three parties known to be creditworthy. This procedure allowed the Bundesbank to collect a unique dataset of information stemming from the balance sheets and the profit and loss accounts of firms (see Stoess (2001), von Kalckreuth (2003) and Doepke et al. (2005) for further details).

Quality standards of the data are particularly high. All mandatory data collected for USTAN have been double-checked by Bundesbank staff. Hence, the data should contain unusually few errors for a micro-data set. One drawback of USTAN is that with the introduction of the EURO, the Bundesbank stopped buying commercial bills and collected firm balance sheet data only irregularly and from publicly available sources. Therefore, the data set stops being useful in 1999. Therefore, we only use data from 1971 to 1998, which because of lagging and firstdifferencing leaves us with essentially 26 year observations from 1973 to 1998.

The coverage of the sample is broad, although it is technically not a representative sample due to the non-random sample design. It was also more common to use bills of exchange in manufacturing and for incorporated companies, which biases our data somewhat towards these kinds of firms. And, of course, the Bundesbank would only rediscount bills with a good rating, so that the set of firms in USTAN is also somewhat biased to financially healthy and larger firms.

Nevertheless, USTAN covers a wide range of firms, since short-term financing through commercial bills of exchange was common practice for many German companies across all business sectors (see Table 16 below for the detailed sectoral composition of our final sample). USTAN also has a broad ownership coverage ranging from incorporated firms as well as privately owned companies, which distinguishes it from the Compustat data. Within the former group USTAN covers both untraded corporations (e.g. limited liability firms, $\mathrm{GmbH}$ ) as well as publicly held companies $(A G)$. Finally, USTAN features also a relatively broad size coverage, as we will show in Table 17 below for our final sample, the creation of which we describe in some detail now.

We start out with the universe of observations in the USTAN data, merging the files for 1971-1986 and 1987-1998. In a first pass, we then drop all balance sheets that are irregular, 
e.g. bankruptcy or closing balance sheets, or stem from a holding (Konzernbilanz). This leaves us with only regular balance sheets (Handelsbilanz or Steuerbilanz). We also drop all firms with missing payroll data or missing or negative sales data, which are basically non-operating firms. A small amount of duplicate balance sheets is removed as well. And finally, we drop the following sectors: hospitality (hotels and restaurants), which has only a small amount of firms in the database, financial and insurance institutions, the mostly public health and education sectors, as well as other public companies like museums, etc. and some other small service industries, such as hair cutters, dry cleaners and funeral homes; ${ }^{31}$ or when sectoral information was missing. The sectoral aggregate we are studying can be roughly characterized as the non-financial private business sector in Germany. This leaves us with an initial data set of 1,764,846 firm-year observations and 259,614 firms. The average number of firms per year is 63,030.

From this initial data set we remove step-by-step more observations, in order to get an economically reasonable data set. We first drop observations from likely East German firms to avoid a break of the series in 1990. We identify a West German firm as a firm that has a West German address or has no address information but enters the sample before 1990. Then we recompute capital stocks with a modified perpetual inventory method (PIM) and employment levels. In the modified PIM we drop a small amount of observations from the top and bottom of the distribution of correction factors for the initial capital stock, see Appendix A.2. Extreme correction factors indicate that constant depreciation is not a good approximation for this particular firm. Such a firm will have had an episode of extraordinary depreciation (e.g. fire, a natural disaster, etc.) and the capital stocks by PIM will be a bad measure of the actual capital after the disaster. We remove observations that do not have a log value added and a log capital stock after PIM. Another large part is removed due to not featuring changes in log firm-level employment, capital and real value added, which obviously requires us to observe firms two years in a row. Then we remove outliers in factor changes and real value added changes. Specifically, we identify as outliers in our sample a firm-year in which the firm level investment rate or log changes in firm-level real value added, employment and capital stock fall outside a three standard deviations band around the firm and sectoral-year mean. Then we compute firm-level Solow residuals (see Appendix A.4 for details) and similarly remove observations with missing log changes in Solow residuals as well as outliers therein. We finally remove - before and after each step of the outlier removal - firms that have less than five observations in firm-level Solow residual changes. We conduct extensive robustness checks of our results to the choices for the outlier and observation thresholds (see Appendix B). Table 15 summarizes, how much observations are dropped in each step.

\footnotetext{
${ }^{31}$ The number of firms from the public sector and these small industries is tiny to begin with, as they did not use commercial bills as a financing instrument. We left out financial and insurance institutions, as they arguably have a very different production function and investment behavior.
} 
Table 15: SAMPLE CREATION

\begin{tabular}{lr}
\hline \hline Criterion & Drops of Firm-Year Observations \\
\hline East Germany & 104,299 \\
Outliers in PIM & 7,539 \\
Missing log value added & 1,349 \\
Missing log capital & 31,819 \\
Missing log-changes in N, K, VA & 161,668 \\
Outliers in factor and VA log-changes & 41,453 \\
Missing log-changes in Solow residual & 126,086 \\
Outliers in Solow residual log-changes & 18,978 \\
Not enough observations & 417,550 \\
\hline Total & 910,741
\end{tabular}

The final sample then consists of 854,105 firm-year observations, which amounts to observations on 72,853 firms and the average observation length of a firm in the sample is 11.7 years. The average number of firms per year is 32,850. The following Tables 16 and 17 as well as 18 show the average sectoral ${ }^{32}$ and the size distributions in our sample, as well as the distributions over the number of observations, respectively.

Table 16: SECTORAL Distribution

\begin{tabular}{llrrr}
\hline \hline & & & Fraction of \\
ID & Sector & Observations & Observations & WZ 2003 \\
\hline 10 & Agriculture & 12,291 & $1.44 \%$ & A, B \\
20 & Energy \& Mining & 4,165 & $0.49 \%$ & C, E \\
31 & Chemical Industry, Oil & 14,721 & $1.72 \%$ & DF, DG \\
32 & Plastics, Rubber & 23,892 & $2.80 \%$ & DH \\
33 & Glass, Ceramics & 28,623 & $3.35 \%$ & DI \\
34 & Metals & 30,591 & $3.58 \%$ & DJ \\
35 & Machinery & 162,407 & $19.01 \%$ & DK, DL, DM, DN \\
36 & Wood, Paper, Printing & 61,672 & $7.22 \%$ & DD, DE \\
37 & Textiles, Leather & 46,173 & $5.41 \%$ & DB, DC \\
38 & Food, Tobacco & 37,708 & $4.41 \%$ & DA \\
40 & Construction & 54,569 & $6.39 \%$ & F \\
61 & Wholesale Trade & 213,071 & $24.95 \%$ & G51 \\
62 & Retail Trade \& Cars & 142,137 & $16.64 \%$ & G50, G51 \\
70 & Transportation \& Communication & 22,085 & $2.59 \%$ & I \\
\hline & Total & 854,105 & &
\end{tabular}

\footnotetext{
${ }^{32} \mathrm{WZ} 2003$ is the industry classification from 2003 that the German national accounting system (Volkswirtschaftliche Gesamtrechnung, VGR) uses.
} 
Table 17: Size Distributions OF FiRMS

\begin{tabular}{|c|c|c|c|c|c|c|c|c|c|}
\hline $\begin{array}{l}\text { Number of } \\
\text { Employees } \\
\text { Fraction }\end{array}$ & $\begin{array}{r}1-4 \\
6.14 \%\end{array}$ & $\begin{array}{r}5-9 \\
9.46 \%\end{array}$ & $\begin{array}{r}10-14 \\
8.24 \%\end{array}$ & $\begin{array}{r}15-19 \\
7.30 \%\end{array}$ & $\begin{array}{r}20-49 \\
26.28 \%\end{array}$ & $\begin{array}{r}50-99 \\
17.04 \%\end{array}$ & $\begin{array}{c}100-249 \\
14.37 \%\end{array}$ & $\begin{array}{r}250-499 \\
5.68 \%\end{array}$ & $\begin{array}{r}500+ \\
5.49 \%\end{array}$ \\
\hline Capital Stock & & & & & & & & & \\
\hline (in 1000 1991-Euro) & $0-299$ & $300-599$ & $600-999$ & $1,000-1,499$ & $1,500-2,499$ & $2,500-4,999$ & $5,000-9,999$ & $10,000-24,999$ & $25,000+$ \\
\hline Fraction & $8.23 \%$ & $9.01 \%$ & $9.67 \%$ & $9.36 \%$ & $13.08 \%$ & $17.71 \%$ & $13.87 \%$ & $11.08 \%$ & $7.99 \%$ \\
\hline $\begin{array}{l}\text { Real Value Added } \\
\text { (in } 1000 \text { 1991-Euro) }\end{array}$ & $0-299$ & $300-499$ & $500-749$ & $750-999$ & $1,000-2,499$ & $2,500-4,999$ & $5,000-9,999$ & $10,000-24,999$ & $25,000+$ \\
\hline Fraction & $6.14 \%$ & $9.96 \%$ & $8.81 \%$ & $7.57 \%$ & $26.02 \%$ & $16.28 \%$ & $11.320 \%$ & $8.25 \%$ & $5.79 \%$ \\
\hline
\end{tabular}

Table 18: OBSERVATION DISTRIBUTION

\begin{tabular}{crrrcrrr}
\hline \hline Obs. per Firm & Firms & Percent & Cum. & Obs. per Firm & Firms & Percent & Cum. \\
\hline 5 & 8,973 & 12.32 & 12.32 & 16 & 2,487 & 3.41 & 78.10 \\
6 & 7,592 & 10.42 & 22.74 & 17 & 2,225 & 3.05 & 81.16 \\
7 & 6,609 & 9.07 & 31.81 & 18 & 2,024 & 2.78 & 83.93 \\
8 & 5,724 & 7.86 & 39.67 & 19 & 1,849 & 2.54 & 86.47 \\
9 & 4,901 & 6.73 & 46.39 & 20 & 1,619 & 2.22 & 88.69 \\
10 & 4,338 & 5.95 & 52.35 & 21 & 1,479 & 2.03 & 90.72 \\
11 & 3,960 & 5.44 & 57.78 & 22 & 1,351 & 1.85 & 92.58 \\
12 & 3,528 & 4.84 & 62.63 & 23 & 1,446 & 1.98 & 94.56 \\
13 & 3,134 & 4.30 & 66.93 & 24 & 988 & 1.36 & 95.92 \\
14 & 3,006 & 4.13 & 71.05 & 25 & 892 & 1.22 & 97.14 \\
15 & 2,647 & 3.63 & 74.69 & 26 & 2081 & 2.86 & 100 \\
\hline
\end{tabular}

How well does the USTAN aggregate represent the non-financial private business sector (NFPBS) in Germany? Table 19 shows that USTAN represents on average $70 \%$ of the value added of the NFPBS, $44 \%$ of its investment, etc. Moreover, USTAN replicates the capital-output ratio of NFPBS rather well, somewhat less so the other canonical ratios, such as the investment rate, average labor productivity and the labor share, which has obviously to do with our larger firm bias in the sample. ${ }^{33}$

\footnotetext{
33 To compute these time-average statistics we only average over the data from 1973 to 1990 , because from then on German national accounting does no longer report West and East Germany separately. For the business cycle statistics we use the post-reunification data, but filter separately before and after this structural break. NFPBS value added is taken from Bruttowertschoepfung in jeweiligen Preisen, table 3.2.1 of VGR, deflated year-by-year by the implicit deflator for aggregate value added, table 3.1.1 of VGR (we apply the same deflator to USTAN data). The base year is always 1991. We experiment also with implicit sector-specific deflators for value added from table 3.2.1 and 3.2.2 of VGR, and results are robust to this. NFPBS investment is Bruttoanlageinvestitionen in jeweiligen Preisen from table 3.2.8.1, deflated with the implicit sector-specific investment price deflators given by
} 
Table 19: USTAN AND THE NFPBS

\begin{tabular}{lccc}
\hline \hline & USTAN/NFPBS & USTAN & NFPBS \\
\hline Value Added & $70 \%$ & - & - \\
Investment & $44 \%$ & - & - \\
Capital & $71 \%$ & - & - \\
Employment & $49 \%$ & - & - \\
Payroll & $54 \%$ & - & - \\
Capital/Value Added & - & 1.544 & 1.496 \\
Investment/Value Added & - & 0.099 & 0.158 \\
Value Added/Employment & - & 52828 & 36859 \\
Payroll/Value Added & - & 0.506 & 0.657 \\
\hline
\end{tabular}

Figure 4 shows that except for a certain overrepresentation of manufacturing and a certain underrepresentation of the transportation and communication sector, USTAN represents the sectoral composition in NFPBS rather well.

Figure 4: Sectoral Composition in USTAN and NFPBS
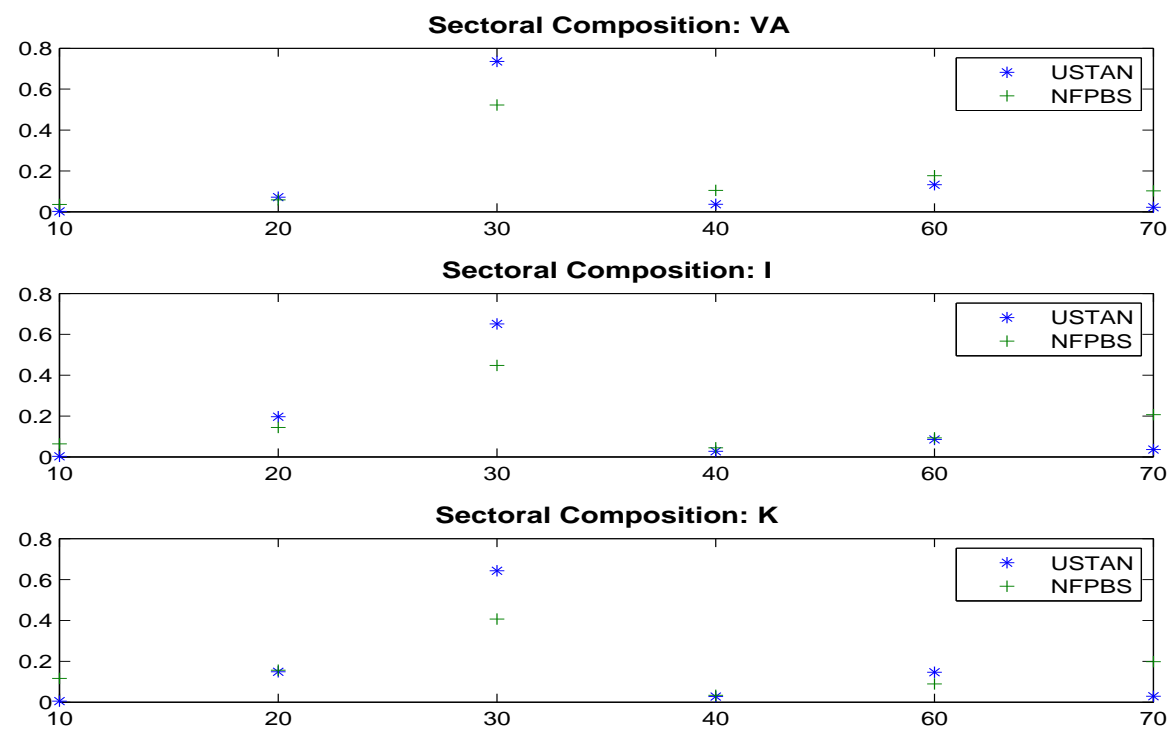

Notes:

Graphs display the fraction of the sum of real value added, investment and capital, respectively, over all firms by 1-digit sector within the USTAN sample over the NFPBS aggregate.

Bruttoanlageinvestitionen - preisbereinigt, a chain index, from table 3.2.9.1, VGR. NFPBS capital is Nettoanlagevermoegen in Preisen von 2000 from table 3.2.19.1, VGR, re-chained to 1991 prices. In both the computation of investment and capital data for USTAN in the PIM we use the implicit sector and capital good specific (equipment and non-residential structures) deflators for investment: tables 3.2.8.2, 3.2.9.2., 3.2.8.3 and 3.2.9.3., VGR. We also experiment with deflating USTAN data with a uniform investment price deflator, the Preisindex der Investitionsgueterproduzenten, source: GP-X002, Statistisches Bundesamt. NFPBS employment is number of employed, Arbeitnehmer, from table 3.2.13, VGR. Finally, payroll is taken from Arbeitnehmerentgelt, table 3.2.10., VGR, deflated by the same general implicit deflator for aggregate value added that we use to deflate value added numbers. 
Figure 5 demonstrates that also the cyclical behavior of USTAN and NFPBS is close. The correlation of the cyclical components of value added is 0.7671 and for the investment rate it is $0.7843 .{ }^{34}$

Figure 5: Cyclical Behavior in USTAN and NFPBS
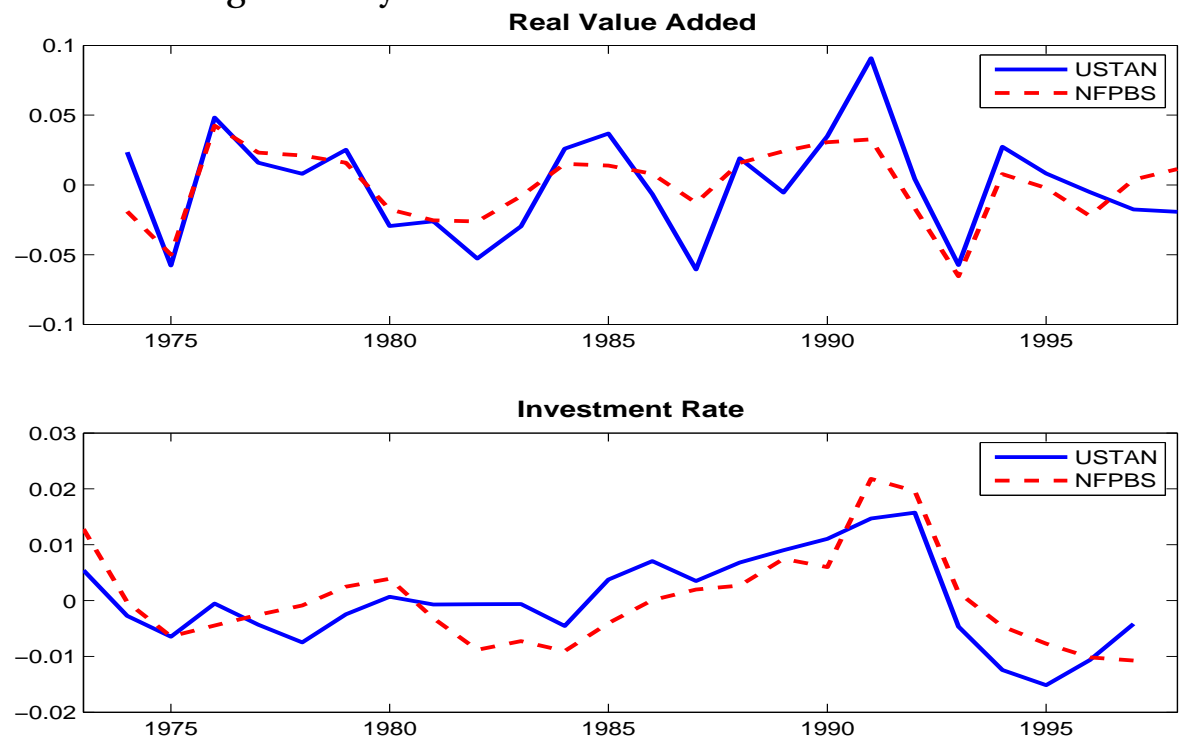

Notes:

Upper panel: time series for the sum of real value added over all firms in the USTAN sample and NFPBS after detrending with logarithmic first differences and a deterministic linear trend.

Lower panel: time series for the sum of investment over all firms in the USTAN sample and NFPBS, divided by the average of the beginning-of-period and end-of-period aggregate capital stocks in USTAN and NFPBS, respectively, after detrending with a deterministic linear trend.

Finally, how does the USTAN investment rate cross-section compare to known data from the U.S.? The following Table 20 compares cross-sectional moments of the USTAN investment rates (for reasons of comparison with only $k_{i, t}$ in the denominator) with the ones reported in Cooper and Haltiwanger (2006) for manufacturing plant-level data. Even though USTAN comprises sectors other than manufacturing and is a firm-level as opposed to a plant-level data set, these histograms are remarkably similar, which lends some optimism to the generalizability of our results to the U.S.

\footnotetext{
${ }^{34}$ We take first differences of log value added and then take out both for it and the investment rate a deterministic linear trend to remove the growth of the USTAN sample over time. The correlation between only the first differences in log value added is still 0.5348 , and 0.4966 , when an $\mathrm{HP}(100)$-filter is applied. The correlation for the raw investment rate series is 0.7089 .
} 
Table 20: USTAN AND LRD MOMENTS

\begin{tabular}{lcc}
\hline \hline Moment & USTAN & LRD \\
\hline Negative Spike (<-20\%) & $0.3 \%$ & $1.8 \%$ \\
Negative Investment (-20\%,-1\%) & $2.6 \%$ & $8.6 \%$ \\
Inaction (-1\%,1\%) & $15.1 \%$ & $8.1 \%$ \\
Positive Investment (1\%,20\%) & $67.7 \%$ & $62.9 \%$ \\
Positive Spike (> 20\%) & $15.4 \%$ & $18.6 \%$ \\
\hline
\end{tabular}

\section{A.2 Capital Stocks}

In order to obtain economically meaningful stocks of capital series for each firm, we have to re-calculate capital stocks in a Perpetual Inventory Method (PIM). The first step is to compute firm-level investment series, $i_{i, t}$, from the corporate balance sheets, which contain data only on accounting capital stocks, $k_{i, t}^{a}$, and accounting total depreciation, $d_{i, t}^{a}$. The following accumulation identity allows to back out nominal firm-level investment: ${ }^{35}$

$$
k_{i, t+1}^{a}=k_{i, t}^{a}-d_{i, t}^{a}+p_{t}^{I} i_{i, t} .
$$

The next step is to recognize that capital stocks from corporate balance sheets are not directly usable for economic analysis for two reasons: 1) accounting depreciation, $d_{i, t}^{a}$, in corporate balance sheets is often motivated by tax reasons and typically higher than economic depreciation, $\delta_{i, t}^{e}$, expressed as a rate; 2$)$ accounting capital stocks are reported at historical prices. Both effects would lead to an underestimation of the real firm-level capital stock, if one were to simply deflate the current accounting capital stock, $k_{i, t}^{a}$, with a current investment price deflator, $p_{t}^{I}$ (assuming that $p_{t}^{I}$ increases over time). We therefore apply a Perpetual Inventory Method (PIM) to compute economic real capital stocks:

$$
\begin{aligned}
k_{i, 1}^{(1)} & =k_{i, 1}^{a} . \\
k_{i, t+1}^{(1)} & =\left(1-\delta_{t}^{e}\right) k_{i, t}^{(1)}+\frac{p_{t}^{I}}{p_{1991}^{I}} i_{i, t} .
\end{aligned}
$$

\footnotetext{
${ }^{35}$ Specifically, $k_{i, t}^{a}$ is the sum of balance sheet items ap65, Technische Anlagen und Maschinen, and ap66, Andere Anlagen, Betriebs-und Geschaeftsausstattung, for equipment; and balance sheet item ap64, Grundstuecke, Bauten, for structures. Since balance sheet data are typically end-of-year stock data, notice that $k_{i, t}^{a}$ is the end-of-period capital stock in year $t-1 . d_{i, t}^{a}$ is profit and loss account item ap156, Abschreibungen auf Sachanlagen und immaterielle Vermoegensgegenstaende des Anlagevermoegens. In contrast to $k_{i, t}^{a}, d_{i, t}^{a}$ is not given for each capital good separately. For the solution of this complication, see below.
} 
$k_{i, 1}^{a}$ is the accounting capital stock in prices of 1991 at the beginning of an uninterrupted sequence of firm observations - if for a firm-year we have a missing investment observation, the PIM is started anew, when the firm appears again in the data set. We estimate $\delta_{t}^{e}$ for each year from national accounting data, $V G R$, separately for equipment and non-residential structures (table 3.1.3, VGR, Nettoanlagevermoegen nach Vermoegensarten in jeweiligen Preisen, Ausruestungen und Nichtwohnbauten; table 3.1.4, VGR, Abschreibungen nach Vermoegensarten in jeweiligen Preisen, Ausruestungen und Nichtwohnbauten). VGR contains sectoral and capital good specific depreciation data only after 1991, which is why we decided to use only capital good specific depreciation rates for the entire time horizon. For the data sources for investment price deflators see footnote 33. The drawback of this procedure is that we do not observe directly capital-good specific $d_{i, t}^{a}$ in the balance sheets (differently from $k_{i, t}^{a}$ ), so that (12) is not directly applicable for the two types of capital goods separately. We therefore split up $d_{i, t}^{a}$ according to the fraction that each capital good accounts for in the book value of total capital, weighting each capital good by its VGR depreciation rate. Creating a capital series for both capital goods this way is mainly meant to provide a better estimate for total capital for each firm, because we finally aggregate up both types of capital into a single capital good at the firm-level.

There is a final complication, which comes through relying on $k_{i, 1}^{a}$ as the starting value of the PIM. It is typically not a good estimate of the productive real capital stock of the firm at that time. Therefore, we calculate the time-average factor $\phi$ (for each sector), by which $k_{i, t}^{(1)}$ is larger than $k_{i, t}^{a}$, and replace $k_{i, 1}^{a}$ by $\phi k_{i, 1}^{a}$ in the perpetual inventory method. We do this iteratively, until $\phi$ converges, i.e. we calculate:

$$
\begin{aligned}
k_{i, t+1}^{(n)} & =\left(1-\delta_{t}^{e}\right) k_{i, t}^{(n)}+\frac{p_{t}^{I}}{p_{1991}^{I}} i_{i, t} \\
k_{i, 1}^{(n)} & =\phi^{(n-1)} k_{i, 1}^{(n-1)} \\
\phi^{(n)} & =(N T)^{-1} \sum_{i, t} \frac{k_{i, t}^{(n)}}{k_{i, t}^{(n-1)}}
\end{aligned}
$$

where $k_{i, t}^{(0)}=k_{i, t}^{a}, \phi^{(0)}=1$. We stop when for each sector and each capital good category $\phi<1.1$.

Since for our purposes we want to compute economic, i.e. productive, capital stocks, we then - as a final step - add to the capital stock series from this iterative PIM the net present value of the real expenditures for renting and leasing equipment and structures. ${ }^{36}$

\footnotetext{
${ }^{36}$ Specifically, we take item ap161, Miet- und Pachtaufwendungen, from the profit and loss accounts, deflate it by the implicit investment good price deflator, which we compute, in turn, from tables 3.2.8.1 and 3.2.9.1 from VGR, and then divide it by a measure of the user cost of capital. The latter is simply the sum of real interest rates for a given year, which - courtesy of the Bundesbank - we compute from nominal interest rates on corporate bonds and ex-post CPI inflation data (the series is available from the authors upon request), and the time-average, accounting capital-good weighted depreciation rate per firm.
} 


\section{A.3 Labor Inputs}

A more particular difficulty with USTAN data is that information on the number of employees is only updated infrequently for some companies, as it is not taken directly from balance sheets, but sampled from supplementary company information. Being no balance sheet item, the employment data is not constrained by legal accounting rules and did not undergo consistency checks by Bundesbank staff. However, in order to compute firm-level Solow residuals, we need some measure of employment.

We base this measure on the payroll data ( wagebill $_{i, t}$ ) from the profit and loss statements (item ap154, Personalaufwand). Payroll data is regulated by accounting standards and is checked for consistency by the Bundesbank using accounting identities. In contrast to the direct employment data, the payroll data is generally considered of high quality. Therefore, we exploit this data to construct a proxy measure for (log) employment $n_{i, t}$ as follows (with a slight abuse of notation, we use $n_{i, t}$ here for log employment).

The idea behind our proxy measure is that we can determine sectoral average wages even though firm level employment is measured with error. Since wage bargaining in Germany is highly centralized, the sectoral average wage is all we need then, since it is a good proxy for firm level wages. Therefore, dividing firm level payroll by the sectoral average wage recovers true firm level employment.

Specifically, we assume that the measurement error in reported log employment, $n_{i, t}^{*},{ }^{37}$ is classical and additive:

$$
n_{i, t}^{*}=n_{i, t}+\varepsilon_{i, t}
$$

Then we decompose the wage per employee, $\omega_{i, t}$, of firm $i$ at time $t$ into two effects. One is determined by a firm-time-specific wage component $w_{i, t}$, and the other one being region-, $r(i, t)$, sector-, $j(i, t)$, and size-class-specific, $s(i, t)$, where $j(i, t), r(i, t)$ and $s(i, t)$ denote that firm $i$ belongs to sector $j$, region $r$ and size-class $s$ at time $t$, respectively. ${ }^{38}$ Thus, we write

$$
\omega_{i, t}=\bar{w}_{j(i, t), r(i, t), s(i, t), t}+w_{i, t}
$$

We denote all firms that belong to sector $j$, region $r$ and size-class $s$ at time $t$ by $I(j, r, s, t)$. Then

\footnotetext{
${ }^{37}$ We use item ap34, Beschaeftigtenzahl im Durchschnitt des Geschaeftsjahres, to measure $n_{i, t}^{*}$, where available.

${ }^{38}$ Specifically, for sectors we use the 2-digit classification in Table 16 in Appendix A.1. For size classes we use terciles of the capital distribution in each year. For the region-specific wage component we proceed as follows: we divide West Germany into three regions, according to zip codes: South with zip codes starting with 7,8,9, except for 98 and 99; Middle with zip codes starting with 4,5,6, except for 48 and 59; North with zip codes starting with 2,3 as well as 48 and 59. However, not all balance sheets feature zip code information, which is why we compute $\widehat{\bar{w}}_{j, r, s, t}$ with and without a region component. For those firms that do not have zip code information or for those firms that are in sector-region-size bins with fewer than 50 observations in a given year, we take the estimate without the region component.
} 
we can estimate a sector-region-size wage component, $\bar{w}_{j, r, s, t}$, as: ${ }^{39}$

$$
\widehat{\bar{w}}_{j, r, s, t}=\frac{1}{\# I(j, r, s, t)} \sum_{i \in I(j, r, s, t)}\left[\log \left(\text { wagebill }_{i, t}\right)-n_{i, t}^{*}\right] .
$$

We then use this estimate of the average wage rate to estimate employment on the basis of the firm's wage bill:

$$
\begin{aligned}
\hat{n}_{i t} & =\log \text { wagebill } i t-\widehat{\bar{w}}_{j, r, s, t} \\
& =n_{i t}+\omega_{i t}-\frac{1}{\# I(j, r, s, t)} \sum_{h \in I(j, r, s, t)}\left(n_{h, t}+\omega_{h, t}-\left(n_{h, t}+\varepsilon_{h, t}\right)\right) \\
& =n_{i t}+w_{i t}-\frac{1}{\# I(j, r, s, t)} \sum_{h \in I(j, r, s, t)}\left(w_{h, t}-\varepsilon_{h, t}\right) \\
& =n_{i t}+w_{i t}+\frac{1}{\# I(j, r, s, t)} \sum_{h \in I(j, r, s, t)} \varepsilon_{h, t .} .
\end{aligned}
$$

The second equality stems from using (18). The next to last equality holds, because one can replace $\omega_{i t}$ by (19), realizing that the $\bar{w}$, which do not depend on a specific firm, cancel. The last equality holds, because, by construction, the average firm-level deviation from a sectorregion-size bin is zero in every year. For \#I $(j, r, s, t)$ large, the average measurement error term $\left(\frac{1}{\# I(j, r, s, t)} \sum_{h \in I(j, r, s, t)} \varepsilon_{h, t}\right)$ is negligible. In addition, since wage bargaining is highly centralized in Germany, also the firm specific wage component, $w_{i t}$, can be expected to be of lesser importance, i.e. the variance $\sigma_{w}^{2}$ is small. In particular it can be expected to be smaller than the initial measurement error in employment stocks. Therefore our measure of employment, $\hat{n}_{i, t}$, should follow real employment, $n_{i, t}$, more closely than $n_{i, t}^{*}$.

To corroborate this claim, we checked our procedure using data from the German social security records at the Institut fuer Arbeitsmarkt- und Berufsforschung (IAB), which provide information on the wage bill and employment at the establishment level. There we observe true employment and wage bills for all plants and the time 1975-2006. Constraining ourselves to the sample period 1975-1998 and to plants with more than 12 employees, i.e. to data comparable to the one of the USTAN data, we find the correlation between $\hat{n}_{i, t}$ and $n_{i, t}$ as well as between $\Delta \hat{n}_{i, t}$ and $\Delta n_{i, t}$ to be fairly high ( $98 \%$ and $94 \%$, respectively). This means that the cross-sectional variance of the firm specific wage innovations $\sigma_{\Delta w}^{2}$ is small (0.0026) compared to the cross-sectional variance of employment changes $\left(\sigma_{\Delta n}^{2}=0.0163, \sigma_{\Delta \hat{n}}^{2}=0.0162\right)$. Finally, a correlation coefficient between mean $\left(\Delta n_{i, t}\right)$ in the USTAN data and the log-change in aggregate NFPBS employment of 0.653 shows also the quality of our employment measure.

\footnotetext{
${ }^{39}$ To estimate $\widehat{\bar{w}}_{j, r, s, t}$ we of course use only those observations, where $n_{i, t}^{*}$, i.e. item ap34, Beschaeftigtenzahl im Durchschnitt des Geschaeftsjahres, is available.
} 


\section{A.4 Solow Residual Calculation}

With the estimated firm-level capital stocks and employment levels we can now compute firmlevel Solow residuals from the logged production function (1). In our baseline specification we estimate the factor elasticities, $v$ and $\theta$, as 1 -digit sector-specific median, pooled over all firmyear observations in a sector, expenditure shares. ${ }^{40}$ Table 21 displays the estimated elasticities. Simulations show that under the null hypothesis of the model the labor elasticity is very accurately estimated by the labor share, whereas the capital elasticity is slightly overestimated by the capital share, which makes our simulations conservative, as we have shown that a lower capital elasticity, i.e. more curvature in the revenue function, will lead to a stronger extensive margin effect, that will make investment dispersion more procyclical (see Section 5.1 for details). Notice that for the aggregate Solow residual calculation in the baseline scenario, for which we use the data sources specified in Footnote 33 in Appendix A.1, we simply use the expenditure shares from manufacturing, as manufacturing is still the largest sector within NFPBS (had we used any weighted median of expenditure shares the result would have been the same). We experiment also with weighted average expenditure shares, both weighted with value added and with employment/capital and using USTAN and NFPBS weights. To come up with a single number for each factor elasticity, we simply take the median of these four weighted averages and use $v=0.5229$ and $\theta=0.2352$. This requires a recalibration of the adjustment costs factor, $\bar{\xi}$, to 0.3 , but the baseline result is not changed: the resulting procyclicality of investment dispersion is 0.6534 , a number very close to the 0.6517 of the baseline scenario and the 0.613 from the data.

Table 21: SECTOR-SPECIFIC EXPENDITURE SHARES

\begin{tabular}{rlrr}
\hline \hline ID & Sector & labor share $v$ & capital share $\theta$ \\
\hline 1 & Agriculture & 0.2182 & 0.7310 \\
2 & Energy \& Mining & 0.3557 & 0.5491 \\
3 & Manufacturing & 0.5565 & 0.2075 \\
4 & Construction & 0.6552 & 0.1771 \\
6 & Trade & 0.4536 & 0.2204 \\
7 & Transport \& Communication & 0.4205 & 0.2896 \\
\hline
\end{tabular}

\footnotetext{
${ }^{40}$ We use profit and loss account item ap153, Rohergebnis, for firm-level value added and deflate it in the baseline scenario with the aggregate value added deflator, but experiment also with sector-specific value added deflators, see Footnote 33 in Appendix A.1 for details. To compute firm-level expenditure shares, we proceed as follows: the labor share is simply total payroll divided by value added (ap154/ap153); capital expenditures, which are then again divided by value added, are the sum of the PIM capital stock and the net present value of renting and leasing expenditures multiplied by the user cost of capital as specified in Footnote 36 in Appendix A.2.
} 


\section{A.5 Two More Graphs}

Figure 6: Data: Time Series of Investment Dispersion and Cyclical Component of GDP - Normalized by their STD

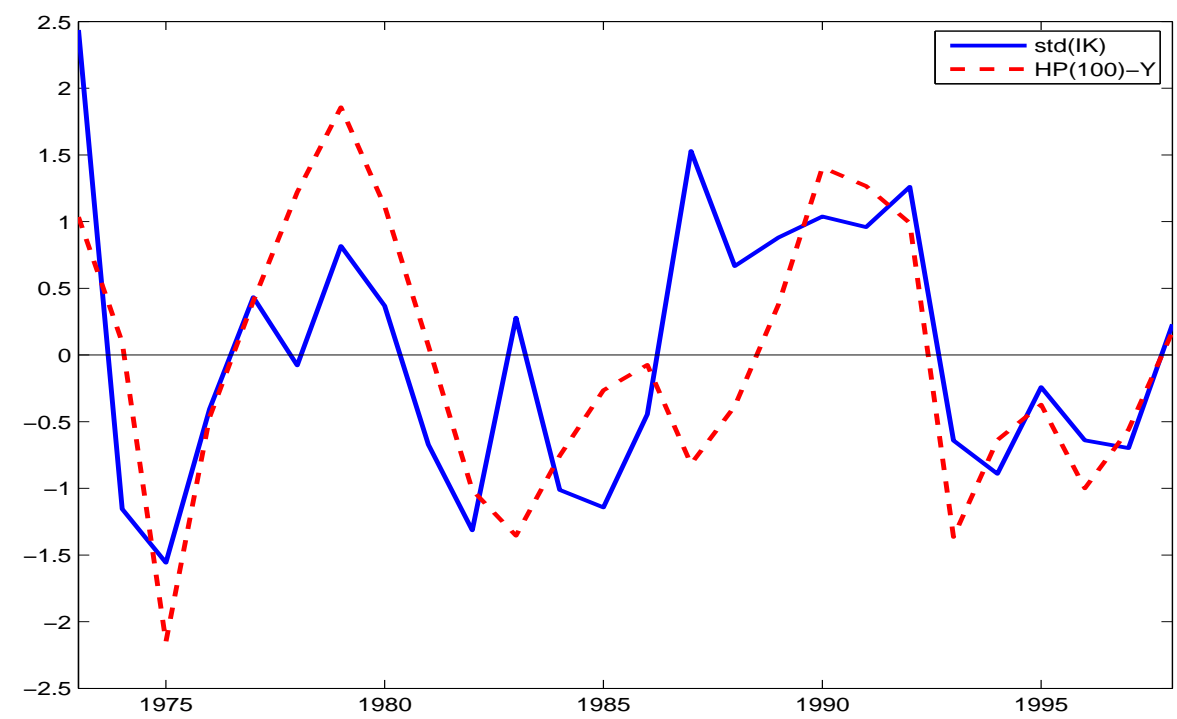

Notes:

Dispersion refers to the cross sectional standard-deviation. The cyclical component of GDP is the HP-filtered output series with a smoothing parameter of 100 .

Figure 7: Baseline Model: Time Series of Investment Dispersion and Cyclical Component of GDP - Normalized by their STD

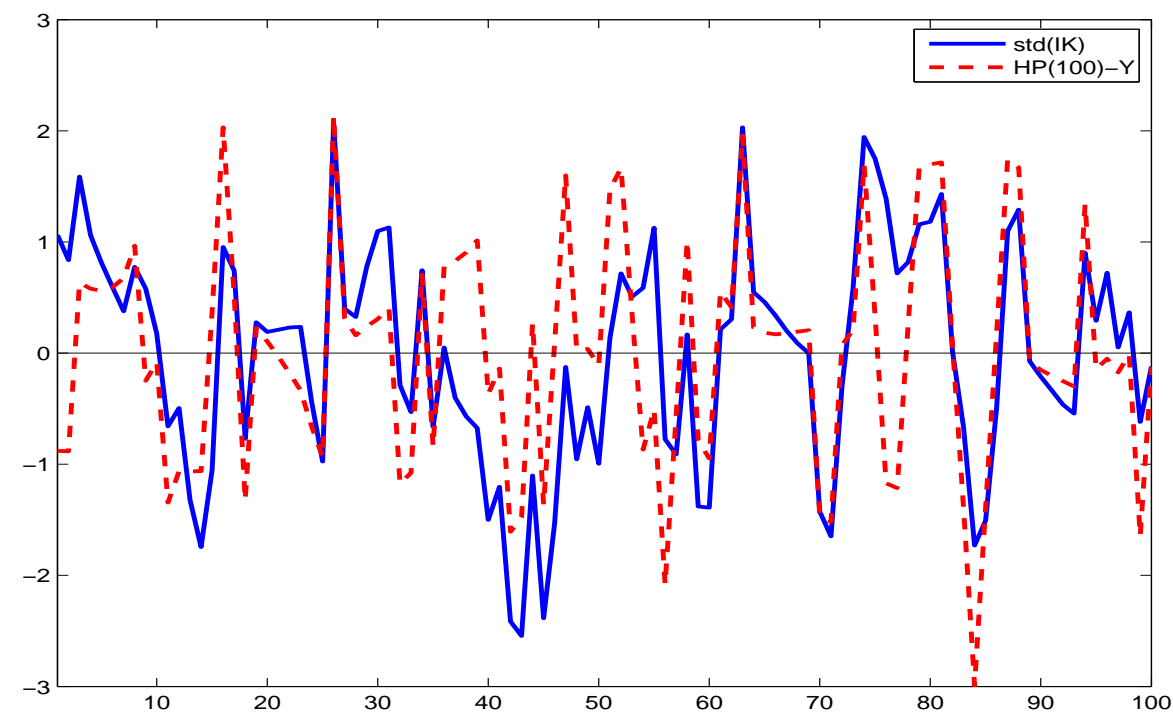

Notes:

Dispersion refers to the cross sectional standard-deviation. The cyclical component of GDP is the HP-filtered output series with a smoothing parameter of 100 . 


\section{A.6 Cross-sectional Dispersion Data}

Table 22: Cross-Sectional Dispersion Data for the InVESTMENT RATE AND THE EmployMENT CHANGE RATE IN THE BASELINE EMPIRICAL SCENARIO

\begin{tabular}{rrr}
\hline \hline Year & $\sigma\left(\frac{i_{i, t}}{0.5 *\left(k_{i, t}+k_{i, t+1}\right)}\right)$ & $\sigma\left(\frac{\Delta n_{i, t}}{0.5 *\left(n_{i, t-1}+n_{i, t}\right)}\right)$ \\
\hline 1973 & $12.163 \%$ & $13.6663 \%$ \\
1974 & $10.1656 \%$ & $14.4443 \%$ \\
1975 & $10.0048 \%$ & $14.4376 \%$ \\
1976 & $10.738 \%$ & $13.93 \%$ \\
1977 & $11.2907 \%$ & $13.2382 \%$ \\
1978 & $11.0666 \%$ & $13.2087 \%$ \\
1979 & $11.6523 \%$ & $13.1194 \%$ \\
1980 & $11.4642 \%$ & $13.0973 \%$ \\
1981 & $10.9353 \%$ & $13.6914 \%$ \\
1982 & $10.6357 \%$ & $13.659 \%$ \\
1983 & $11.6238 \%$ & $13.5832 \%$ \\
1984 & $10.9507 \%$ & $13.2013 \%$ \\
1985 & $10.9456 \%$ & $13.5816 \%$ \\
1986 & $11.4179 \%$ & $13.2644 \%$ \\
1987 & $12.6242 \%$ & $13.4395 \%$ \\
1988 & $12.1978 \%$ & $13.0941 \%$ \\
1989 & $12.3912 \%$ & $12.7371 \%$ \\
1990 & $12.5519 \%$ & $13.3669 \%$ \\
1991 & $12.577 \%$ & $13.2751 \%$ \\
1992 & $12.8208 \%$ & $12.9378 \%$ \\
1993 & $11.7963 \%$ & $13.1612 \%$ \\
1994 & $11.7228 \%$ & $12.9218 \%$ \\
1995 & $12.1667 \%$ & $12.6971 \%$ \\
1996 & $12.0077 \%$ & $12.8086 \%$ \\
1997 & $12.0444 \%$ & $12.264 \%$ \\
1998 & $12.6487 \%$ & $12.1935 \%$ \\
\hline & &
\end{tabular}

Notes: $\sigma$ : cross-sectional standard deviation of the within-transformed data. No detrending. The corresponding data for $\sigma\left(\Delta \log \epsilon_{i, t}\right)$ and $\sigma\left(\Delta \log y_{i, t}\right)$ can be found in Bachmann and Bayer (2009). 


\section{B Appendix B - Robustness of Cross-sectional Cyclicality}

In this appendix we check the robustness of the main empirical finding of this paper - the procyclicality of investment dispersion - to sample selection and variable construction. First, we use an aggregate price deflator for investment goods (see Footnote 33 in Appendix A.1 for details) in the perpetual inventory method instead of sectoral deflators separately for equipment and structures. Second, we employ a stricter outlier removal criterion of 2.5 standard deviations around the firm- and year-specific mean in Solow residual and value added innovations, as well as investment rates and employment changes. Third, we use a more liberal outlier criterion using 5 standard deviations instead of $3 .{ }^{41}$ Fourth, we employ a specification, where we assume that an outlier above 3 standard deviations means a merger and, subsequently, treat these firms as new firms in addition to removing them in the year, where the outlier occurs. Fifth, we restrict the sample to firms with at least 20 observations in first differences, in order to make sure that the cyclical effects we find are not due to cyclical variations in the sample composition. Sixth, we use all the firms that we observe at least twice with first differences. ${ }^{42}$ Finally, we carry out a more standard PIM that simply uses the reported capital stocks in the first year of observation for a firm, instead of solving a fixed point problem in correction factors (see Appendix A.2 for details). As one can see from Table 23, the results are robust to all these alternative sampling procedures; in particular, the robust procyclicality of investment dispersion is not driven by a change in the cyclicality of the dispersion of the driving force.

Table 23: Cyclicality of Cross-Sectional Investment Dispersion - Data Treatment

\begin{tabular}{lcc}
\hline \hline Treatment & $\rho\left(\sigma\left(\frac{i_{i, t}}{0.5 *\left(k_{i, t}+k_{i, t+1}\right)}\right), H P(100)-Y\right)$ & $\rho\left(\sigma\left(\Delta \log \epsilon_{i, t}\right), H P(100)-Y\right)$ \\
\hline Baseline & 0.613 & -0.481 \\
\hline Uniform price index for I-goods & 0.637 & -0.480 \\
Stricter outlier removal & 0.606 & -0.499 \\
Looser outlier removal & 0.549 & -0.476 \\
Stricter Merger Criterion & 0.617 & -0.485 \\
Longer in sample & 0.568 & -0.341 \\
Shorter in sample & 0.624 & -0.485 \\
Standard Perpetual Inventory & 0.630 & -0.492 \\
\hline
\end{tabular}

\footnotetext{
${ }^{41}$ This lowers the number of dropped firm-year observations due to outliers in factor and value added changes from 41,453 to 17,205, and the ones due to outliers in Solow residual changes from 18,978 to 5,526. This leaves the total number of firm-year observations at 908,476 and the total number of firms in the sample at 76,464.

${ }^{42}$ This lowers the number of dropped firm-year observations due to not satisfying the minimum observation requirement from 417,550 to 158,950 . This leaves the total number of firm-year observations at 971,308 and the total number of firms in the sample at 114,528.
} 


\section{Appendix C - Aggregate Statistics}

Table 24: Aggregate Business Cycle Statistics for the Baseline Calibration

\begin{tabular}{lcccc}
\hline \hline Moment/Aggregate Quantity & $Y$ & $C$ & $I$ & $N$ \\
\hline Standard Deviation & $3.37 \%(2.30 \%)$ & $1.24 \%(1.79 \%)$ & $15.30 \%(4.37 \%)$ & $2.47 \%(1.80 \%)$ \\
Relative Standard Deviation & 1 & $0.37(0.78)$ & $4.55(1.90)$ & $0.73(0.78)$ \\
Persistence & $0.30(0.48)$ & $0.62(0.67)$ & $0.23(0.42)$ & $0.21(0.61)$ \\
Correlation with $Y$ & 1 & $0.80(0.66)$ & $0.97(0.83)$ & $0.95(0.68)$ \\
\hline
\end{tabular}

Notes:

Business cycle statistics of aggregate output, $Y$, consumption $C$, investment $I$ and employment $N$. $N$ in the model includes the amount of labor used to adjust the firms' capital stocks. All variables are logged and then HP-filtered with a smoothing parameter of 100. The first numbers in a column refer to a simulation of the model over $T=$ 1500 periods. Numbers in brackets refer to German aggregate NFPBS data. Persistence refers to the first order autocorrelation.

All variables are logged and then HP-filtered with a smoothing parameter of 100 . The numbers in brackets are the statistics from the data, from the sectoral aggregate that corresponds to the USTAN data: the non-financial private business sector (NFPBS). They are gathered from German sectoral national accounting data (see Footnote 33 in Appendix A.1 for details). Real private consumption data are private Konsumausgaben, a chain index with base year in 1991, from table 3.2 in the $V G R$. The model employment variable includes the amount of labor used to adjust the firms' capital stocks.

In our baseline calibration, the economy is overall too volatile, which we attribute partly to the fact that we compute the aggregate Solow residual process from the private non-financial business sector and not from the overall economy. Nevertheless, both the too high volatility numbers, as well as the too low persistence numbers as well as the discrepancy between model and the data in the relative standard deviations - relative to $\operatorname{std}(Y)$ - of aggregate consumption and aggregate investment show that there is not enough smoothing in the baseline calibration, which is a well-known problem of the standard RBC model. Our baseline model cannot improve that, as the level of non-convexities essentially puts it in a parameter range, where the Khan and Thomas neutrality result still holds (see Khan and Thomas, 2008). Since this paper is exclusively concerned with cross-sectional dynamics, for which - as we have shown - non-convexities matter already at a level, where they would be near-neutral for aggregate dynamics, we do not view this as a problem for our main result. More smoothing could be implemented through a standard quadratic adjustment cost element on top of the fixed cost, however at both a substantial computational burden and at the expense of cleanness of exposition. In fact, quadratic 
adjustment costs would work very similarly to an increase in curvature in the maximized-out revenue function, which, as we have shown, puts more emphasis on the procyclical extensive margin and will only strengthen our mechanism. Our robustness checks include a case, where we decrease the volatility of the aggregate Solow residual in order to match the volatility of aggregate output. This is the most conservative scenario, as this puts relatively more weight on the second-moment shocks, i.e. the countercyclicality of the dispersion in the Solow residual innovations, and would make it - all things equal - harder for the extensive margin effect in the lumpy model to generate procyclicality of investment dispersion. Row five in Table 14 in Section 5.2 shows that this only slightly changes our baseline result. To summarize: the aggregate shortcomings of the model are similar to the one in the standard RBC model, but based on our robustness checks we view them as mainly orthogonal to the cross-sectional dynamics that this paper focusses on. 